\title{
Die SCHLIESSUNG DES HANSISCHEN KONTORS IN NOVGOROD IM JAHRE 1494 IM KONTEXT DER BEZIEHUNGEN DES GROSS- FÜRSTEN VON MOSKAU ZU MAXIMILIAN VON HABSBURG
}

\author{
von Marina Bessudnova
}

Der St. Peterhof (russ.: Deutscher Hof) in Groß-Novgorod, eines der vier Hansekontore, die entlang dem großen hansischen Weg von London bis zu den russischen Grenzen gegründet wurden, war der nördlichste Stützpunkt des Hansehandels in Osteuropa und der Ort eines lebhaften Warenaustauschs, der seit der Wikingerzeit als eine unsichtbare Brücke zwischen den russischen Ländern und dem Westen im Mittelalter bestand. Die russischen Hauptexportartikel wie kostbare Pelze, Honig, Wachs usw. waren auf den europäischen Märkten außerordentlich geschätzt. Reiche Novgoroder, darunter Bojaren, Geistliche und Kaufleute, erwarben ihrerseits auch gern Handwerkserzeugnisse des ,lateinischen" Westens. Dank dieses Handels entstand der Gospodin Velikij Novgorod („Herr Groß-Novgorod“) und entwickelte sich zu einer sehr bedeutenden Macht. Der Handel brachte den Kaufleuten - Russen und Deutschen - große Gewinne ein, so dass der Peterhof nie leer stand.

In den Geschäftsbeziehungen zwischen Novgorod und der Hanse gab es zuweilen scharfe Auseinandersetzungen. Die Novgoroder und die Hansen bemühten sich jedoch, den gegenseitigen Ansprüchen durch Verhandlungen und durch den Abschluss wechselseitig vorteilhafter Verträge gerecht zu werden, z. B. „Nieburs Kreuzküssung“ von 1392, durch die die Hansen die Möglichkeit erhielten, ohne Behinderungen nach Novgorod zu fahren und Waren zu kaufen. Russische „Gäste“ bekamen freien Zugang (,„̌istyj put',,) nach Livland und verbrachten lange Zeit in den livländischen Städten, wo bei den orthodoxen Kirchen ,russische Dörfer" entstanden. Im Jahre 1472 schloss Novgorod mit der Hanse einen weiteren Vertrag ab, der bei der Entwicklung des russisch-livländischen Handels eine große Rolle spielte.'

\footnotetext{
' Dazu ausführlich Leopold K. GOETZ, Deutsch-russische Handelsgeschichte des Mittelalters, Lübeck 1922: Paul JOHANSEN, Der hansische Rußlandhandel, insbesondere nach Nov-
} 
Nachdem Novgorod 1478 dem Moskauer Staat gewaltsam eingegliedert worden war und die Reste seiner ehemaligen Unabhängigkeit schnell verlor, änderte sich der Charakter der novgorodisch-hansischen Beziehungen. Jetzt sollten nicht nur die politischen, sondern auch die wirtschaftlichen Kontakte der ehemals mächtigsten Stadt Russlands der Generalstrategie des Großfürsten von Moskau, Ivan III. Vasil'evič (1462-1505), entsprechen. Von 1478 bis 1494 war der Peterhof von den Repressalien, mit denen Novgorod damals überflutet wurde, weitgehend verschont geblieben. Der Großfürst bestätigte sogar alle hansischen Vorrechte, die im Handelsvertrag von 1472 standen, aber die unsichere Lage zwang deutsche Kaufleute, den Peterhof zu verlassen und ihren Handel einzuschränken. ${ }^{2}$ Im Jahre 1487 wurde der neue Handelsvertrag zwischen der Hanse und den Novgoroder Statthaltern, hinter denen die Gestalt des Moskauer Herrschers leicht zu erraten war, besiegelt; ${ }^{3}$ mit ihm wurden die wichtigsten hansischen Vorrechte für die nächsten 20 Jahre festgelegt. Sieben Jahre später aber war das hansische Kontor in Novgorod geschlossen. Am 6 . November 1494 wurden alle seine Bewohner, darunter Kaufleute, ihre Gesellen, Priester und in Novgorod das Russische erlernende junge Leute, auf Befehl Ivans III. verhaftet. Das ganze Vermögen einschließlich der für den Verkauf eingeführten Waren und der Ausstattung der St.-Peterskirche wurden beschlagnahmt. Am 14. November verhaftete man die livländischen Gesandten, den Revaler Gottschalk Remmelingrode und den Dorpater Thomas Schrowe, die nach der Audienz bei dem Großfürsten von Moskau nach Hause aufgebrochen waren. Als Antwort darauf ordneten die Stadträte Rigas und Revals an, alle in ihren Städten anwesenden russi-

gorod, in kritischer Betrachtung, in: Die deutsche Hanse als Mittler zwischen Ost und West. Köln 1963, S. 39-57: Anna L. CHOROŠKEviČ. Torgovlja Velikogo Novgoroda s Pribaltikoj I Zapadnoj Evropoj v XIV-XV vekach (Der Handel Groß-Novgorods mit dem Baltikum und Westeuropa im 14. und 15. Jahrhundert), Moskau 1963; Natalija A. KAZAKovA, Russkolivonskie i russko-ganzejskie otnošenija. Konec XIV-načalo XVI v. (Die russisch-livländischen und russisch-hansischen Beziehungen. Ende des 14. - Anfang des 16. Jh.), Leningrad 1975; Elena A. RYBINA. Inozemnye dvory v Novgorode XII-XVII vv. (Die ausländischen Höfe in Novgorod im 12.-17. Jahrhundert), Moskau 1986; Norbert ANGERMANN, Die Hanse und Rußland, in: Tausend Jahre Nachbarschaft. Rußland und die Deutschen, zusammengestellt in Verbindung mit Alfred Eisfeld von Manfred Hellmann, München 1988, S. 273-276; Erik TibI:RG, Moscow, Livonia and the Hanseatic League 1487-155), Stockholm 1995; Norbert Angermann, Klaus Friedland (Hg.), Novgorod: Markt und Kontor der Hanse. Küln 2002; Anna L. ChoRošKevič, Der deutsche Hof in Novgorod und die deutsche Herberge (Fondaco dei Tedeschi) in Venedig im 13./14. Jahrhundert. Eine vergleichende Vorstudie, in: Ortwin Pelc und Gertrud Pickhan (Hg.), Zwischen Lübeck und Novgorod. Wirtschaft, Politik und Kultur im Ostseeraum vom frühen Mittelalter bis ins 20. Jahrhundert. Norbert Angermann zum 60. Geburtstag, Lüneburg 1996, S. 67-87.

${ }^{2}$ Norbert Angermann. Die Bedeutung Livlands für die Hanse, in: Ders. (Hg.), Die Hanse und der deutsche Osten, Lüneburg 1990, S. 97-116, hier S. 102-103.

${ }^{3}$ HR III, 2. 136, S. 117-119. 
schen Kaufleute festzunehmen und ihre Waren mit Arrest zu belegen. ${ }^{4}$ Ohne Zweifel lösten gerade diese Vorfälle in der Folge die Kettenreaktion der politischen Zusammenstöße im Ostseegebiet aus, weshalb die Vorstellung von einem tiefgehenden Einschnitt im Hinblick auf das ,dominium maris Baltici" viel differenzierter zu betrachten ist.

Die Frage nach den Motiven, die Großfürst Ivan dabei leiteten, ist bisher ungelöst, was vor allem auf die nicht immer objektiven und ziemlich widersprüchlichen Quellen zurückzuführen ist. Es wird damit deutlich erkennbar, dass die Zeitgenossen selbst kein genaues Verständnis von den Ursachen der so unerfreulichen Entwicklung hatten, aber es ist klar: Das alles machte auf Deutschland und besonders auf Livland einen schockierenden Eindruck, der leicht zu verstehen ist. Denn die plötzliche SchlieBung des Hansekontors war nicht nur eine grobe Verletzung des russischhansischen Handelsvertrags von 1487, der die Garantien für die ausländischen Kaufleute und die Erhaltung des Peterhofs enthielt, sondern bedeutete auch die Zerstörung der traditionellen Handelsbeziehungen und eine Annullierung gegenseitiger Geschäftsvereinbarungen, ebenso wie sie Zweifel an den Aussichten für die Weiterentwicklung des Handels mit den Russen nährte. Die Schließung des Hofes wurde also ohne formalrechtliche Voraussetzungen, die offiziell erst im Jahre 1497 erklärt wurden. ${ }^{5}$ durchgeführt: darum versuchten die Hansen aus Livland und Deutschland dies wenigstens auf der Grundlage der realen politischen Interessen des Großfürsten zu deuten, aber das mangelnde Verständnis für den Vorgang führte sofort zur Entstehung verschiedener Erklärungen, die dann in den Urkunden und Chroniken ihren Niederschlag fanden.

Die früheste dieser Erklärungen ist im Schreiben des Revaler Ratmanns Remmelingrode zu finden, der zu dieser Zeit samt den anderen Bewohnern des Peterhofs im Novgoroder Gefängnis festgehalten wurde. Ende 1494 schrieb er an den Rat der Stadt Reval über die Umstände seiner Verhaftung und erzählte, die Hansen in Novgorod wären wegen des Zorns des Großfürsten gegen die livländischen Städte festgenommen worden, nachdem ein Musscouwer in Reval hingerichtet worden sei. ${ }^{6}$ Remmelingrode gab hier zweifellos die Fassung wieder, die er wie auch sein Gefährte Schrowe ${ }^{7}$ von den Russen, vielleicht von einem der Novgoroder

\footnotetext{
${ }^{4}$ Liv-, Est- und Kurländisches Urkundenbuch. Abt. 2 (im Folgenden: LEKUB II). Bd. 1. Riga 1900, Nr. 84.

5Im Brief des „Kanzlers“ des Großfürsten an den Ordensmeisters Plettenberg vom 20. März 1497. HR III, 4, 1 1, 3; LEKUB II, 1, 507.

${ }^{6}$ LEKUB II, 1, 95, S. 75f.

${ }^{7}$ Der Dorpater Schrowe wurde bald nach der Verhaftung freigelassen, aber vor seiner Abreise sprach mit ihm ein Novgoroder Statthalter und äußerte sich ihm gegenüber fast ebenso, wie es im Brief von Remmelingrode stand. HR III, 3, $433 \$$ 16-28; LEKUB II, I, 34.
} 
Machthaber, erhalten hatte. Die Erklärung, man hätte in den livländischen Städten die Untertanen und Gesandten des Großfürsten unterdrückt und gekränkt, wurde bei den russisch-livländischen Verhandlungen 1498 zum Anklagepunkt gegen die Livländer ${ }^{8}$ und fand so Eingang in die livländischen und sonstigen deutschen Chroniken. ${ }^{9}$ Die russischen Geschichtsdenkmäler des 16. Jahrhunderts (letopisi) betrachteten das Novgoroder Ereignis in derselben Weise. ${ }^{10}$

Gleichzeitig verbreiteten die Livländer, die enger als die „überseeischen Hansen" mit dem Novgoroder Kontor verbunden waren, schnell die Vermutung, dass die Schließung des Peterhofs durch die russisch-dänische, gegen Schweden gerichtete Vereinbarung von 1493 vorbereitet worden sei. " Diese Version erschien einige Zeit später in den schwedischen Chroniken von Olaus und Laurentius Petri. ${ }^{12}$ Im Großen und Ganzen mutet die Nachricht zuverlässig an, weil der dänische König seine gegen die Hanse gerichtete Politik am Rande eines Krieges betrieb. Er beschränkte den deutschen Handel in seinen Ländern und unterstützte die Seeräuber, die hansische Schiffe beraubten. Die Schließung des Novgoroder Hansekontors wäre dann ein Zeichen des Wohlwollens des Großfürsten gegenüber seinem neuen Verbündeten oder eine Bürgschaft für seine Allianzverpflichtungen gewesen. ${ }^{13}$ Dabei ist jedoch darauf hinzuweisen, dass es sich

\footnotetext{
${ }^{8}$ HUB $11,1054 \$ 4,6,10$; vgl. § 3; LEKUB II, 1, 647.

${ }^{9}$ Eynne Schonne Hystorie van vunderlyken gescheffthen der herren tho Lyfflanth myth den russen unde tartaren, in: Archiv für die Geschichte Liv-, Est- und Kurlands 8, 1861, S. 113-265, hier S. 138-141; Albert Krantz Wandalia, Frankfurt 1580, Lib. XIV, cap. 22, S. 327; Balthasar Ruissow's I ivländische Chronik, in: Scriptores rerum I.ivonicarum, Bd. 2, Riga 1845, S. 1-194, hier S. 32; Franz NYENSTAEDT"S Livländische Chronik nebst dessen Handbuch, in: Monumenta Livoniae antiquae, Bd. 2, Riga 1839, S.1-160, hier S. 32.

${ }^{10}$ Polnoe sobranie russkich letipisej (Vollständige Sammlung der russischen Chroniken, im folgenden: PSRL), Bd. 28: Letopisnyj svod 1497 g. Letopisnyj svod 1518 g. (Uvarovskaja letopis'), Moskau 1963, S. 160 (svod von 1497); PSRL. Bd. 27: Nikanorovskaja letopis'. Sokraščennye letopisnye svody konca XV veka, Moskau 1962, S. 366.

${ }^{11}$ "Ock hebbe wii waraffige tidinge van personen unlanges van Muszkouw erdelet, dat de grotforste sick mit dem hochgebaren etc. heren koninghe to Dennemarken up dit lant vorbunden hebbe, dat Jacob Hunningkhusen, dar jegenwordich syende und van dene grotforsten marcklich mit liggenden grunden begifftiget, zolle mede warke gestellet hebben; unde ock wo ernstaffich desulve grotforste sick mi bussen, slangen unde krichaffitigen weren gesterket sii, dat alles is to befruchtende anders nernen tegen dan dit arme lanth" - so schrieben die Dorpater an Reval im November 1494 (LEKUB II, I. 83). Ein Gerücht war im Umlauf, der König Johann von Dänemark verspräche dem Großfürsten anläßlich der Verlobung seines Sohnes mit der Tochter des Moskauer Herrschers, ihm Finnland und Livland zu schenken (LEKUB II, 1. 119).

${ }^{12}$ Olaii PETRI Svenska Chronica [...], in: Scriptores rerum sveciarum medii aevi, T. 1, Upsala 1818, p. 328; Laurentii PETRI Chronica svecana [...], in: Scriptores rerum sveciarum medii aevi, T. 2, Upsala 1828, p. 136.

${ }^{13}$ Sergej M. SOLOV'EV. Istorija Rossii s drevnejšich vremen (Die Russlands Geschichte seit den ältesten Zeiten), Moskau 1960, Bd. 3, S. 130-131; Georgij V. FORSTEN, Bor'ba iz-za
} 
hier nur um eine Hypothese handelt, die quellenmäßig nicht bestätigt. ist. Die Meinung, dass der Vertrag 1493 eine heimliche Abmachung über die Schließung des Peterhofs enthielt, ist bis heute unbewiesen. Genauso hypothetisch ist eine andere Annahme des Historikers Nikolaj Michajlovič Karamzin, der meinte, dass der Befehl zur Schließung des Hansekontors in Novgorod von dem brennenden Wunsch des „Herrschers der ganzen Ruś“, Ivans III., getragen war, die Reste der novgorodischen Autonomie zu vernichten und die dort noch existierende Opposition unter seine Gewalt zu zwingen. ${ }^{14}$

Es sei hierbei erwähnt, dass die Eskalation des russisch-livländischen Konfliktes Ende des 15. Jahrhunderts im Ganzen unklar und von Mythen durchdrungen ist. Die deutschbaltischen Historiker des 19. und 20. Jahrhunderts betrachteten dieses Problem in dem festen Rahmen einer weit verbreiteten Theorie von der Auseinandersetzung zweier verschiedener politischer Systeme, d.h. cincrseits einer Konföderation geistlicher Staaten mit dem größten Meister des livländischen Deutschordenszweiges Wolter von Plettenberg (1494-1535) an der Spitze und anderseits einer ,außerordentlich große(n) militärische(n) Macht“ (Otto von Rutenberg). Offen gestanden, bei jedem, dem die Umstände des „Kampfes um das Baltikum“ am Ende des 15. und während des 16. Jahrhunderts bekannt sind, ruft ein derartiger Standpunkt keinen Widerspruch hervor. Man muss davon ausgehen, dass die internationalen Gegensätze, die sich im Ostseegebiet zuweilen erkennen lassen, sich in jenem Moment rasch zu entwickeln begannen, als der junge, aber bereits über eigene geopolitische Interessen verfügende russische Staat die internationale Arena betrat. AuBerdem war der „Kampf um die Ostsee“ im 16.-18. Jahrhundert für Russland tatsächlich ein „Kampf um Livland“.

Die Schreiben bezüglich der Kriegshilfe für Livland, die der Ordensmeister Wolter von Plettenberg 1495-1502 nach Europa schickte, haben zu der Vermutung geführt, die Schließung des Kontors wäre durch die gegen Livland gerichteten Expansionsabsichten Ivans III. oder wenigstens durch seine

gospodstva na baltijskom more v XV i XVI stoletijach (Der Kampf um die Herrschaft über die Ostsee im 15. und 16. Jahrhundert), St.-Petersburg 1884, S. 156; W. MolleruP, Dänemarks Beziehungen zu Livland, Berlin 1884. S. 30; Konstantin V. BASıLEVı̌̌, Vnešnjaja politika Russkogo centralizovannogo gosudarstva vtoroj poloviny XV v. (Die Außenpolitik des Russischen zentralisierten Staates der zweiten Hälfte des 15. Jhs.), Moskau 1952, S. 383; Knut Rasmussen, Dansk-russiske forbindelser 50) år, København 1964, S. 11; Anna L. ChorošKeviČ. Russkoe gosudarstvo v sisteme meždunarodnych otnošenij konca XV - nacala XVI vv. (Der russische Staat im System der internationallen Beziehungen Ende des 15.Anfang des 16. Jhs.), Moskau 1980, S. 69-70.

${ }^{14}$ Nikolaj M. KARAmZIN. Istorija gosudarstva Rossijskogo (Die Geschichte des Russischen Staates), Moskau 1993, Bd. 5. S. 282. So auch GoETZ, Deutsch-russische Handelsgeschichte (wie Anm. 1), S. 187; Phillippe Doll.inger, La Hanse, Paris 1964, S. 414. 
Erpressungspolitik gegenüber Livland zu erklären. Dieser Standpunkt ist für die deutschbaltische und sonstige deutsche Historiographie typisch. ${ }^{15}$ Die gegenwärtigen ausländischen Kollegen milderten im Verlauf der letzten drei Jahrzehnte ihr Urteil über den Radikalismus Ivans III. wesentlich, erklären aber die Aufhebung des Peterhofs weiterhin mit der politischen Strategie Ivans, die zur Stärkung der russischen Position im Baltikum führte. ${ }^{16}$ Dazu ist nur zu bemerken, dass die russischen Quellen aus den späten 80er und frühen 90er Jahren des 15. Jahrhunderts keinen näheren Hinweis dazu geben. Heutzutage können wir nicht behaupten, dass Ivan III. im Jahre 1494 wirklich einen Krieg gegen Livland vorhatte.

Bezüglich der Briefe Wolters von Plettenberg ist nicht auszuschließen, eher sogar wahrscheinlich, dass sie keine wirklich zuverlässigen Quellen sind. Man muss berücksichtigen, dass Plettenberg, der über die Lage an der russisch-livländischen Grenze gut informiert war, keine sicheren von der russischen politischen und militärischen Führung stammenden Auskünfte erhielt und sich deshalb häufig nur auf Berichte der Spione stützte, die in den Pskover und Novgoroder Grenzregionen tätig waren, oder auf eigene Wahrnehmungen. ${ }^{17}$ Der Meister hatte auch einen Grund zu übertreiben: Weil er das Geld dringend brauchte und um den nötigen Effekt erzielen zu können, könnte er manchmal durchaus zu weit gegangen sein. Außerdem beteiligte er sich in den 90er Jahren des 15. Jahrhunderts, angeregt vom Hochmeister des Deutschen Ordens Johann von Tiefen, unmittelbar an der Kampagne zur Rettung der Ordensvorrechte, die (wie auch das Existenzrecht der Ordensstaaten in Preußen und Livland) damals der Bischof von

${ }^{15}$ Hermann Hildebrand, Die hansisch-livländische Gesandschafi das Jahres 1494 und die Schließung des deutschen Hofs zu Nowgorod, in: Baltische Monatsschrift, 20, 1871, S. 115-136: Harald COSAK, Livland und Rußland zur Zeit des Ordensmeisters Johann Freitag, in: HGbll. 48, 1923, S. 1-60; 51, 1927, S. 72-115; 52, 1928, S. 81-121, hier 52, 1928, S. 109-110; Leonid ARBusow, Grundriss der Geschichte Liv-, Est- und Kurlands, Riga 1918, S. 129: Wilhelm LENZ, Die auswärtige Politik des livländischen Ordensmeisters Wolter von Plettenberg bis 1510, Riga 1928, S. 7-9; Ruth KENTMANN, Livland im russisch-litauschen Konflikt. Die Grundlegung seiner Neutralitätspolitik. 1494-1514, in: Beitrage zur Kunde Estlands, 4, 3/4, 1929, S. 6-7.

"Erik Tiberg, Moskau. Livland und die Hanse 1487-1547, in: HGbll. 93. 1975, S. 13-70, hier S. 30-34. 36-38; J. RABA. Der Außenhandel als Faktor der russischen Außenpolitik an der Schwelle der Neuzeit. in: Forschungen zur europäischen Geschichte, Berlin 1980, S. 127; Elke WIMMER, Die Russlandspolitik Wolters von Plettenberg, in: Norbert ANGERMANN (Hg.). Wolter von Plettenberg, der größte Ordensmeister Livlands, Lüneburg 1985, S. 71-100, hier S. 80-81; Norbert ANGERMANN, Deutsche Kaufleute in Novgorod im 16. und 17. Jahrhundert, in: Novgorod: Markt und Kontor der Hanse (wie Anm. 1), S. 99-115, hier S. 102-104.

${ }^{17}$ Marina Bessudnova. Dejsivija razvedyvatel'noj služby Livonskogo ordena $v$ predelach novgorodskoj zemli na rubeže XV-XVI vekov (Die Aufklärungsaktionen des Deutschen Ordens im Novgoroder Land an der Wende vom 15. zum 16. Jahrhundert), in: Čelo, Bd. 3 (37), Groß-Novgorod 2006, S. 26-30. 
Ermland Lukas von Watzenrode bestritt. ${ }^{18}$ Um seine Privilegien zu erhalten, musste der Orden seine ursprüngliche Identität unter Beweis stellen, die noch im 13. Jahrhundert im Rahmen der Vorstellungen über den ,heiligen Krieg" gegen die Heiden entstanden war. Unter diesen Umständen entsprach die Beschwörung der Gefahr eines Krieges mit den „russischen Schismatikern" eher mehr der momentanen Situation und könnte dem Reich der politisch-ideologischen Spekulationen zugerechnet werden.

Was die russische Geschichtsschreibung betrifft, sieht die Sache etwas anders aus. Seit Sergej Michajlovič Solov'ev (1820-1879) geht die Tendenz dahin, die historischen Prozesse in Russland und im Westen zu synchronisieren, woraus sich die Vorstellung von der ökonomischen Notwendigkeit des Vordringens Russlands bis zu den Küsten der Ostsee ergab, die später die sowjetische Historiographie übernahm. Im Zusammenhang mit dem Beitritt der baltischen Republiken zur UdSSR im Jahre 1940 bekam dieses Thema für sie eine besondere Aktualität und große politische $\mathrm{Bc}$ deutung. Die These von der ,äußerste(n) Notwendigkeit“ für Russland, den Zugang zur Ostsee zu bekommen“, und von der positiven Richtung seines Kampfes darum wurde zum Dogma. Daraus folgte die Vorstellung von der Absicht des Moskauer Großfürsten Ivan III., das Handelsmonopol der Hanse im Ostseegebiet zu brechen, in deren Folge der Peterhof vernichtet worden sei. ${ }^{19}$ Diese Idee wurde in den 1970er und 80er Jahren von Natalija Aleksandrovna Kazakova entwickelt, ${ }^{20}$ und diese Meinung vertreten viele Historiker in Russland noch heute. ${ }^{21}$ Allerdings kam es in den letzten Jahren auch zu einigen Veränderungen: die Einsicht, dass Russland im 16. und um so mehr im 15. Jahrhundert gegenüber dem Westeuropa der Renaissance und der Reformation ,unzeitgemäß“" war, ${ }^{22}$ wächst allmählich

\footnotetext{
${ }^{18}$ Karol GóRSKI, Lukas von Watzenrode. Życie i działność 1447-15I2, Wrocław 1973.

${ }^{19}$ Sergej V. BACHRUŠIN. Razgrom nemeckogo ordena v Pribaltike Ivanom IV (Die Vernichtung des Deutschen Ordens im Ostseegebiet durch Ivan IV.), in: Istoričeskij žurnal, 1941, 11-12, S. 71-77; Jurij V. Got'E, Baltijskij vorpos v XIII-XVI vv. (Die baltische Frage im 13.-16. Jahrhundert), in: Istorik-marksist, 1941, 6, S. 87-95; etc.

${ }^{20}$ KaZAKovA, Russko-livonskie i russko-ganzejskie otnošenija (wie Anm. 1), S. 261-273; DIES., Danija. Rossija i Livonija na rubeže XV I XVI stoletij (Dänemark, Russland und Livland an der Wende vom 15. zum 16. Jahrhundert), in: Skandinavskij sbornik 25, 1980, S. 107-117; DIES., Ešče raz o zakrytii ganzejskogo dvora v Novgorode v 1494 g. (Noch einmal über die Schließung der Hansehofes in Novgorod im Jahre 1494), in: Novgorodskij istoričeskij sbornik 2 (12), 1984, S. 177-187.

${ }^{21}$ Aleksandr A. ZıMIN, Rossija na rubeže XV-XVI stoletij (Russland um die Wende des 15. z.um 16. Jahrhundert), Moskau 1982, S. 55-75; Jurij G. ALEKSEEv, U kormila Rossijskogo gosudarstva (Am Ruder des Russischen Staates), Moskau 1998. S. 68; Nikolaj S. BoriSOV, Ivan III., Moskau 2006, S. 501-535.

${ }^{22}$ Michail M. KROM, Roždenie gosudarstva Novogo vremeni v Rossii i v Evrope: sravnitel'no-istoričeskaja perspektiva (Die Entstehung des neuzeitlichen Staates in Russland und in Europa: eine vergleichende historische Perspektive), in: Trudy kafedry istorii Rossii s drevnejšych vremen do XX veka, Bd. I, St.-Petersburg 2006, S. 27-36, hier 35.
} 
auch bei den russischen Gelehrten. Nach den letzten Werken von Anna Leonidovna Choroškevič und Aleksandr Il'ič Filjuškin ist offensichtlich, dass die wirtschaftlichen Zielsetzungen in der Außenpolitik der Moskauer Herrscher des 15. und 16. Jahrhunderts nicht genügend Gewicht hatten. um die Strategie dieser Politik zu bestimmen. ${ }^{23}$

Es kann daher kein Zweifel bestehen, dass die ideologischen Zwänge die sowjetischen Historiker erheblich daran hinderten, die Geschichte des Ostseegebietes objektiv wahrzunehmen, aber es ließ sich in der damaligen Zeit nicht ändern. Die Geschichte der baltischen Länder galt zeitweilig als Bestandteil der Geschichte der UdSSR; infolgedessen wurde ihr mittelalterlicher Teil nicht von Mediävisten, sondern von Spezialisten der russischen Geschichte erforscht, die sich hauptsächlich auf russische Quellen, nämlich Chroniken (letopisi), Verträge und Gesandtschaftsbücher stützten. Die livländischen und westeuropäischen Quellen wurden von ihnen meistens nur auszugsweise und manchmal willkürlich ausgewertet. Indessen, wie schon oben erwähnt, spiegelten die Chroniken und anderen russischen Quellen bei der Darstellung der Ereignisse den offiziellen Standpunkt wider. Die SchlieBung des Peterhofs in Novgorod gilt als eine gegen die hansische Willkür gerichtete Schutzmaßnahme, die damit begründet wird, dass der Großfürst von Moskau mit den ungerechten Bedingungen des russisch-hansischen Handels unzufrieden war und die Absicht hatte, durch die Stärkung der russischen Stellung im Baltikum das hansische Monopol zu zerstören. Also ist es ganz klar, dass die in den Chroniken erhaltene Erzählung vom Großfürsten stammte und dank der Bemühungen seiner Dienstleute ins Bewusstsein der Zeitgenossen eingeprägt wurde. Um das Wesen dieser Fassung richtig zu verstehen, muss man wissen, dass das russische Rechtsbewusstsein zur damaligen Zeit durch die Sentenz „Das wissen Gott und der Großfürst ${ }^{\text {‘24 }}$ bestimmt war, die die Suche nach irgendwelchen weiteren Ursachen des Geschehens überflüssig machte. Man kann noch hinzufügen, dass die bemerkenswerte Einförmigkeit der Nachrichten in verschiedenen russischen Texten $^{25}$ die Existenz einer einheitlichen Informationsquelle vermuten lässt.

\footnotetext{
${ }^{23}$ Anna L. CHOROŠKEVIČ, Rossija v sisteme meždunarodnych otnošenij serediny XVI veka (Russland im System der internationallen Beziehungen in der Mitte des 16. Jahrhunderts), Moskau 2003; Aleksandr I. FILJuŠKIN, Diskursy Livonskoj vojny (Die Diskurse über den Livländischen Krieg). in: Ab imperio: Teorija $\mathrm{i}$ istorija nacional'nostej i nacionalizma $v$ postsovetskom prostranstve 2001, 4, S. 43-79.

${ }^{24}$,Dat wet Godt unde de grotfforste" - mit diesen Worten beantworteten die russischen Gesandten die Fragen des Ordensmeisters Plettenberg bezüglich der novgorodischen Verhaftungen im April 1495 (LEKUB II, 1, 204, S. 161).

${ }^{25}$ A. Vostokov bemerkte schon im 19. Jahrhundert, dass die Angaben der russischen Chroniken des 16. Jahrhunderts einander ziemlich ähnelten. A. Ch. Vostokov. Opisanie Rum'ancevskogo muzeuma (Die Beschreibung des Museums von Rum'anzev), St.-Petersburg 1842, S. 362.
} 
Das Rätsel der Schließung des Novgoroder Hansekontors im Jahre 1494 ist also bis heute nicht gelöst; alle diesem Thema gewidmeten Theorien sind hypothetisch und anfechtbar. Ich habe nicht die Absicht, sie hier zu widerlegen, möchte jedoch meinerseits als Hypothese noch eine Variante der Problemlösung vorschlagen, um aus den ,alten Gleisen“ herauszukommen und das Problem unter einem anderen Aspekt zu behandeln. Beginnen wir mit der Bemerkung, dass alle bislang genannten Theorien, trotz ihrer offenkundigen Unterschiede, auf die gemeinsame Meinung zurückgehen, dass die baltische Politik Ivans III. ein eigenständiger Teil seiner Außenpolitik war und eine sehr wichtige Rolle spielte. Die dies bezeugenden Tatsachen sind jedoch nicht zahlreich. Es sind dies: 1. die Briefe des Ordensmeisters Wolter von Plettenberg (und die jeweiligen Antworten darauf) mit der Beschreibung der ,russischen Gefahr", deren Zielrichtung oben erwähnt wurde; 2. der Bau der Festung Ivangorod, die man für einen Stadthafen, gewissermaßen für den Prototyp Sankt-Petersburgs hält, obwohl eine solche Funktion dieser Festung Ende des 15. Jahrhunderts mehr als zweifelhaft ist; 3 . die Schließung des Peterhofs in Novgorod (darüber unten) und 4. der russisch-schwedische Krieg 1495-1497, obwohl dessen Ziel bis heute unklar ist. ${ }^{26}$

Es kann also durchaus bezweifelt werden, ob die Ostsee Ende des 15. Jahrhunderts zum Interessengebiet der Großmacht Moskau wurde. Was aber, wenn man das hier behandelte Ereignis in seinen historischen Kontext stellt und vor dem Hintergrund der erweiterten Problematik, die mit der Regierungszeit Ivans III. verbunden ist, untersucht? Es ist vollkommen auBer Acht gelassen worden, dass die Moskauer Herrscher bis in die 20er Jahre des 16. Jahrhunderts ganz andere Aufgaben zu bewältigten hatten, die mit der Vereinigung der russischen Länder verbunden waren. Nachdem Ivan III. die Prinzessin Sophia Palaiologa geheiratet und kaiserliche Denkweisen übernommen hatte, richtete er seine Hauptbemühungen auf die Wiedererlangung seines „Vatererbes“, der Kiever Ruś, um dieses dann mit Moskau als neuem Zentrum in sein Reich zu verwandeln. Die endgültige Befreiung seines Staates von der tatarischen Oberherrschaft (1480), die Einverleibungen Groß-Novgorods (1478), Tveŕs (1485) und Vjatkas (1489), ebenso auch die Umwandlung Pskovs und Kazans in abhängige Territorien gaben Ivan III. das Recht, den Titel „Herrscher der ganzen Ruś“ zu beanspruchen; seit den 8()er Jahren erschien dieser Titel zum ersten Mal in den russischen Staatsurkunden und in der diplomatischen Korrespondenz. ${ }^{27}$

\footnotetext{
${ }^{26} \mathrm{~N}$. Borisov meint mit Recht, dieser Krieg wäre „fragwürdig hinsichtlich seiner ZweckmäBigkeit“. Borısov, Ivan III. (wie Anm. 21), S. 513.

${ }^{27}$ Dazu ausführlich CHOROŠKEVIČ, Russkoe gosudarstvo v sisteme meždunarodnych otnošenij (wie Anm. 13), S. 78-101; ZIMIN, Rossija na rubeže XV-XVI stoletij (wie Anm. 21),
} 
Das Ausland nahm den neuen Titel des Moskauer Herrschers ziemlich ruhig zur Kenntnis. In den schriftlichen Quellen des Auslands wurde Ivan III. manchmal „Kaiser" genannt, weil der Charakter seiner Macht in der Sicht der Europäer ihm das Recht auf diesen Titel verlieh. Er unterwarf viele bislang souveräne Länder und hielt alle Verwaltungsbefugnisse in seinen Händen. ${ }^{28}$ Ein katholischer Herrscher wehrte sich gegen den „kaiserlichen“ Status des „Moskowiters“ jedoch heftig: der König von Polen und Großfürst von Litauen Kasimir IV., dem ein bedeutender Teil der westrussischen Länder unter Einschluss von Kiev und Smolensk gehörte und der sich infolgedessen auch „Herrscher über Russen“ (,Russkij“) nannte. Mit Recht bestritt er den Anspruch Ivans III., weiter russische Länder zu vereinigen, sowie dessen Anschlag auf die Unversehrtheit seines Staates, weil der Großfürst von Moskau seine Absichten nur auf Kosten Litauens verwirklichen konnte. Weil außerdem beide Herrscher den gleichen Titel „Großfürst“ trugen, hätte der Zusatz „Herrscher der ganzen Ruś“ zum Beweis der niedrigeren Stellung des Großfürsten von Litauen ausgenutzt werden können. Um seine Ansprüche zu verwirklichen, wollte Ivan III. den schweren Kampf mit den mächtigen Jagiellonen antreten. Der Großfürst von Moskau war im ausreichenden Maß Realist und erkannte klar, dass ihm diesmal die Auseinandersetzung mit einem starken zentralisierten Staat bevorstand, der wenig an seine vorhergehenden Gegner, nämlich russische Fürsten, die Novgoroder ,feudale Republik“ oder tatarische „Zaren“, erinnerte.

Die Schwere der Aufgabe forderte von ihm, alle seine Kräfte darauf zu richten und sich sorgfältig auf den entscheidenden Angriff gegen Litauen vorzubereiten. Er hielt sich zeitweilig aus den großen Militärkonflikten heraus und widmete sich erstens der Koalitionsbildung gegen die Jagiellonen, die alle Hauptrichtungen seiner Außenpolitik (Beziehungen mit den Krimtataren, der Walachei, Ungarn, später auch mit dem Reich) einbezogen, und zweitens dem „titular-terminologischen“ (Choroškevič) Streit wegen des Titels „Herrscher der ganzen Ruś, der die außerordentliche Bedeutung seiner Macht beweisen konnte. Die Anerkennung dieses Titels im Westen hätte ihm einen starken Trumpf im Kampf gegen Litauen in die Hand gegeben. Allerdings waren die diplomatischen Kontakte der Großfürsten von Moskau mit der katholischen Welt sehr bescheiden - mit

S. 55-75; AlEKSEEv, U kormila Rossijskogo gosudarstva (wie Anm. 21); BoRISOv, Ivan III. (wie Anm. 21), S. 198-381.

${ }^{28}$ Aleksandr I. FILJUŠKIN, Pročtenie titula pravitelej Russkogo gosudarstva v XV-XVI vv. na meždunarodnoj arene (Die Wahrnehmung des Titels der Herrscher des russischen Staates des 15. und 16. Jahrhunderts in der internationalen Arena), in: Trudy kafedry istorii Rossii (wie Anm. 21), S. 557-575, hier S. 559. 
Litauen und Livland (durch Vermittlung von Novgorod und Pskov), mit Ungarn (seit Mitte der 1480er Jahre). Man kann behaupten, dass die europäischen Herrscher sich nicht beeilten, ihre Botschafter zum Hof des Großfürsten zu schicken, weil die Moskauer Ruś ihnen damals wenig bekannt und dementsprechend wenig interessant für sie war. ${ }^{29}$ Unter diesen Umständen wäre der Beistand des Kaisers des Heiligen Römischen Reiches, Friedrichs III., für ihn von außerordentlicher Bedeutung gewesen und hätte einen Schritt zur Anerkennung seines Titels als „Herrscher der ganzen Ruś“ in Europa bedeuten können. Angemerkt sei, dass die christlichen Herrscher die höchste (königliche) Würde laut europäischer Tradition nur als Verleihung vom Kaiser oder Papst erwerben konnten.

Darum war die Ankunft des schlesischen Ritters Nikolaus Poppel 1486 in Moskau am Hof des Großfürsten ein bemerkenswertes Ereignis. Seinen Worten nach reiste er seit 1468 als Privatperson durch Europa, obwohl er einen von Kaiser Friedrich 111. besiegelten Brief dabei hatte, ${ }^{30}$ der die Aufmerksamkeit der großfürstlichen Umgebung auf sich zog. Damit begann die Geschichte der diplomatischen Beziehungen zwischen Moskau und dem Deutschen Reich, deren erste Phase nur bis 1493 dauerte, aber infolge ihrer Ungewöhnlichkeit sowohl von den Zeitgenossen als auch von den Forschern zur Kenntnis genommen wurde. Die Informationen dazu findet man vor allem in Quellen aus dem Archiv des Moskauer Außenund Gesandtschaftsamtes, des „Posol'skij Prikaz“; dieses enthält Schreiben über die Ankunft der ausländischen Botschafter, über den Verlauf der Verhandlungen, über die Audienzen beim Großfürsten, ebenso Briefe mit Instruktionen, die die ins Ausland abreisenden russischen Botschafter vom ihm erhalten hatten, ihre Berichte über erzielte Ergebnisse und die Information, die sie in fremden Ländern bekommen hatten. Das alles wurde in Form der so genannten Gesandtschaftsakten (,,posol'skie dela“), Tagebücher der Gesandten (,,statejnie listi") oder Papierrollen (,stolbcy) aufbewahrt und seit Ende des 15. Jahrhunderts zu Sammelbänden, sog. Gesandtschaftsbüchern (,,posol'skie knigi“) zusammengefügt. Seit 1851 wurden diese Schriftstücke im neunbändigen Sammelwerk „,Denkmäler der diplomatischen Verbindungen des alten Russland mit den ausländischen Mächten" veröffentlicht. ${ }^{31}$ Der erste Band beginnt mit dem Bericht über

29 In europäischen Reiseführern vom Anfang des 16. Jahrhunderts nahm die Beschreibung Russlands wenig Platz ein: als seine Hauptstadt nannte man gewöhnlich nicht Moskau, sondern Novgorod. Dazu die Instructio manuductionem prestans in cartam itinerarum Martini Hilacomili (1511).

${ }^{30}$ Zur Biographic von Poppel vgl. Joseph FledLER, Nikolaus Poppel, erster Gesandter Österreichs in Russland. Wien 1857.

${ }^{31}$ Pamjatniki diplomatičeskich snošenij drevnej Rossii s deržavami inostrannymi. T. 1. Pamjatniki diplomatičeskich snošenij s Imperiej Rimskoj (Denkmäler der diplomatischen 
die Aufnahme Poppels durch die Moskauer Beamten 1489. Informationen über die Verhandlungen kann man auch in einigen russischen und deutschen Chroniken, ${ }^{32}$ hansischen Urkunden sowie im Wiener Haus-, Hofund Staatsarchiv (HHSA) finden; ohne die Gesandtschaftsbücher ergeben sie jedoch kein genaues Bild über den gesamten Verlauf der Verhandlungen.

Die Geschichte der Beziehungen zwischen Ivan III. und den Habsburgern an der Wende von den 80er zu den 90er Jahren des 15. Jahrhunderts wurde in der Fachliteratur vor allem in Bezug auf die Koalitionsbildung gegen die Jagiellonen erörtert. ${ }^{33}$ Nur zwei Mal haben die Historiker den Forschungsrahmen ein bisschen ausgeweitet: John Fennell beobachtete, dass der Termin der hier erwähnten Verhandlungen mit der Periode der stärksten Begünstigung des russisch-hansischen Handels übereinstimmte, die in der Politik Ivans III. gewährt wurde ${ }^{34}$ Einige Zeit später erforschte Elke Wimmer das im Verlauf der Verhandlungen ab und zu berührte ,livländische" Thema. ${ }^{35}$ Diese zwei Richtungen halte ich für außerordentlich wichtig, weil sie die Möglichkeit eröffnen, das Rätsel der Schließung des Peterhofs durch die Berücksichtigung der Außenpolitik Ivans III. neu zu erklären und auf die veralteten Schablonen zu verzichten.

Im Rahmen der sich entwickelnden Beziehungen zwischen Ivan III. und dem Reich kam es im Frühjahr 1489 zu einem neuerlichen Besuch Poppels, jetzt jedoch als eines bevollmächtigen Gesandten des Kaisers und seines Sohnes, des Römischen Königs Maximilian von Habsburg. Im Na-

Beziehungen des alten Russland mit den ausländischen Mächten. Bd. 1. Denkmäler der diplomatischen Beziehungen mit dem Römischen Reich) (im folgenden: PDS I), St.-Petersburg 1851 .

${ }^{32}$ Voskresenskaja letopis', in: PSRL, Bd. 8, Moskau 2001, S. 218-227; vgl. Patriaršaja ili Nikonovskaja letopis', in: PSRL, Bd. 12, Moskau 2000, S. 220-223, 230-233, 237; Sofijskaja letopis', in: PSRL. Bd. 6. T. 2, Moskau 2001, S. 326, 328. 331, 333; Christoph LEHMANN, Chronica der Freyen Reichs-Stadt Speier, Frankfurt a. M. 1698, S. 928-931.

${ }^{13}$ Joseph FIEDLER, Die Allianz zwischen Kaiser Maximilian I. und Vasilij Ivanovič, Grossfürsten von Russland von dem Jahr 1514, Wien 1863, S. 4; P. KARGE, Friedrich's 1Il. und Maximilian's Beziehungen zu Moskau, in: Deutsche Zeitschrift für Geschichtswissenschaft 9, H. 2, 1893; Hans UeBERSBERGER, Österreich und Russland seit dem Ende der 15. Jahrhunderts, Wien 1906; BAZILEVIČ, Vnešnjaja politika Russkogo centralizovannogo gosudarstva (wie Anm. 13), S. 255-281; Vladimir N. BALJAZIN, Russko-imperskie otnošenija v pervoj treti XVI v. (Die russisch-reichsdeutschen Beziehungen im ersten Drittel des 16. Jahrhunderts), in: Voprosy istoriografii i istočnikovedenija slavjano-germanskich otnošenij, Moskau 1973, S. 147-175; CHORošKEVIČ. Russkoe gosudarstvo v sisteme meždunarodnych otnošenij (wie Anm. 13). S. 96-98, 137-138; Elke WIMMER, Livland - ein Problem der habsburgischrussischen Beziehungen in der Zeit Maximilians I.?, in: Norbert Angermann (Hg.), Deutschland - Livland - Russland. Ihre Beziehnungen vom 15. bis zum 17. Jahrhundert. Lüneburg 1988, S. 53-110.

${ }^{34}$ John L. I. FEnNeLl, Ivan the Great of Moscow, London 1963, S. 119, 130.

${ }^{35}$ WIMMER, Livland - ein Problem der HABSBURGISCH-russischen Beziehungen (wie Anm. $31)$. 
men des Letzteren bot er dem Moskauer Großfürsten „große Gnade und Freundschaft" an, nämlich einen Bündnisvorschlag gegen die polnischlitauischen Jagiellonen, zudem die Ehe zwischen einer der Töchter des Großfürsten mit dem Neffen Kaiser Friedrichs III., dem Markgrafen (,Markrabij" ${ }^{\text {, }}$ ) Albrecht von Baden. Die zweite Tochter sollte mit Sigismund von Brandenburg oder Johann von Sachsen verheiratet werden. ${ }^{36}$ Solche Ehebündnisse gefielen dem Großfürsten nicht, weil sie ihn auf die Ebene eines kaiserlichen Vasallen gestellt und seiner Meinung nach seine Würde gemindert hätten; deswegen wurden sie abgelehnt. Während der Abschiedsaudienz bat Poppel den Großfüsten, nachdem dieser versprochen hatte, seine Botschafter für die Bestätigung ,der Liebe und der Freundschaft" an den Hof Friedrichs III. zu entsenden, mit ihm privat zu sprechen; als seine Bitte gewährt wurde, meldete er, dass der Kaiser dem Großfürsten von Moskau vorschlug, sein Dienstmann (,služebnik“) zu werden, und dass er ihm im Gegenzug die königliche Würde und den dazugehörigen Titel verleihen werde. ${ }^{37}$

Ein solcher Schritt hätte die Inkorporation des Moskauer Staates in die politische Struktur des Heiligen Römischen Reiches bedeutet; der Moskauer Herrscher wäre dadurch hierarchisch dem Kaiser untergeordnet worden. Iwan III. empfand sich aber nicht nur als selbstständiger Herrscher, sondern auch als den westlichen Königen und sogar dem Kaiser ebenbürtig. In seiner Antwort, die Poppel durch den Djaken Fedor Kuricyn erhielt, brachte der Großfürst seine Vorstellung vom eigenen Gottesgnadentum deutlich zum Ausdruck: „Wir sind durch Gottes Erbarmen Herrscher in unserem Lande von Anfang an seit unseren ersten Vorfahren. Gott hat uns eingesetzt, ihn bitten wir, dass er uns und unseren Kindern in Ewigkeit die Herrschaft gebe wie jetzt, eine andere Einsetzung haben wir nie gewünscht und wünschen sie auch jetzt nicht" ${ }^{38}$ Damit war das Prinzip der staatlichen Souveränität zum ersten Mal in der Geschichte Russlands formuliert worden, das die Abhängigkeit des Moskauer Staates von ausländischen Mächten vollständig ausschloss. Der Vorschlag Poppels war damit abgelehnt. Im weiteren Verlauf der Verhandlungen mit Maximilian gab Ivan zu verstehen, dass er als gleichberechtigter Partner des Kaisers und seines Sohnes zu betrachten sei; darum nannte er sich in den diplomatischen Schreiben „Großfürst und Großer Herrscher" (,velikij knjaź $i$ velikij gosudar").

Anzumerken ist, dass sich Poppel vor diesem wichtigen Gespräch, in dem es um die Größe und die Vorrechte der kaiserlichen Macht ging,

\footnotetext{
${ }^{36}$ PDS I, Sp. 6, 9, 12.

${ }^{37}$ PDS I, Sp. 10-11.

${ }^{38}$ PDS I, Sp. 12.
} 
unerwartet als Anwalt der livländischen Interessen präsentiert hatte. Seinen Worten nach wirkte er im Auftrag des livländischen Ordensmeisters Johann Freitag von Loringhoven, mit dem er sich auf dem Weg nach Moskau getroffen hatte. Der Meister bat ihn, dem Großfürsten Klagen über die Angriffe auf das Ordensland durch die Pskover vorzutragen, und Poppel glaubte dabei, dass seiner Bitte größerer Nachdruck verliehen würde, wenn er darauf hinwies, dass die in Livland lebenden Deutschen die „Untertanen unseres Herrschers" seien (,nemci Vifljandskie zemli poddani sut' gosudarja našego ") ${ }^{39}$ und darum mit seinem Schutz rechnen konnten. Der Hauptstandpunkt des Großfürsten von Moskau, gegenüber niemandem eine Beschränkung seiner Prärogative hinzunehmen, war ihm leider nicht bekannt. Iwan III. lehnte es ab, dieses Thema zu besprechen. Das Problem des russisch-livländischen Konflikts wurde so zum ersten Mal während der Verhandlungen berührt.

Die Grenze, die Livland von den Gebieten Novgorods und Pskovs trennte, war sehr eigenartig. Die Lebhaftigkeit der wirtschaftlichen Kontakte der die livländische Konföderation bildenden Staaten mit den russischen Fürstentümern sowie das Fehlen einer dynastischen Politik, die in den Beziehungen zwischen den beiden russischen „feudalen Republiken“ und den geistlichen Herrschern Livlands im Prinzip unmöglich war, bedingten eine ziemlich kleine Zahl an ernsten territorialen Ansprüchen der Nachbarn gegeneinander. Die Grenzkonflikte trugen vor allem lokalen Charakter und waren durch die Undeutlichkeit der Grenze und dementsprechend ihre „Durchsichtigkeit“" verursacht. ${ }^{40}$ Ob die von Kaiser Friedrich III. für Poppel erlassene Instruktion diesen Punkt betraf, wissen wir nicht, weil es keinen originalen Text dazu gibt und sein Inhalt uns nur dank der russischen Nacherzählung bekannt ist. Alles übrigens, was Poppel aus diesem Anlass gesagt hatte, entsprach völlig der Realität der Politik der Habsburger dem Deutschen Orden gegenüber. ${ }^{41}$ Trotz seines Wunsches, mit dem Kaiser aus dem Westen zu verhandeln, war Ivan III. jedoch weit davon entfernt, in der Frage um die Rechte des Oberschiedsrichters in seinem Streit mit Livland Maximilian gegenüber nachzugeben. Der Römische König beharrte nicht darauf, da Livland nach Elke Wimmer in der Politik der Habsburger nur als „Tauschmünze“, noch nicht als Streitobjekt diente. ${ }^{42}$

\footnotetext{
${ }^{39}$ PDS I. Sp. 9-10.

${ }^{40}$ Anti Selart, Zur Sozialgeschichte der Ordensgrenze Estlands im Mittelalter, in: ZfO 47, 1998, S. 520-543.

4l Vgl. Marian Biskup, Der Deutsche Orden im Banne der habsburgischen Politik in der zweiten Hälfte des 15. und zu Beginn des 16. Jahrhunderts, in: Ritterorden zwischen geistlicher und weltlicher Macht im Mittelalter (Ordines Militares - Colloquia Torunensia Hiscorica V), Toruń 1990, S. 101-126.
} 
Das Interesse der Moskauer Regierung am Aufbau engerer Beziehungen zum Reich zeigte sich an der Eile, mit der Ivan III. eine Antwortbotschaft vorbereitete. Poppel war kaum dazu gekommen, Moskau zu verlassen, als hinter ihm die russische Gesandtschaft mit den Diplomaten Jurij Trachaniot, Ivan Chalepa und Kostja Aksent'ev an der Spitze aufbrach. Sie fuhr über Novgorod. Reval und Lübeck nach Deutschland. Am 25. Juli 1489 wurden die Gesandten des Großfürsten von Kaiser Friedrich III. während des Reichstages in Frankfurt feierlich empfangen. Sie brachten dem Kaiser und seinem Sohn kostbare Geschenke und versicherten den Wunsch des Großfürsten, die freundlichen Verhältnisse mit dem Reich zu erhalten. ${ }^{4 \hat{}}$ Ein besonderes Schreiben war dabei an Maximilian adressiert. Der Großfürst von Moskau ließ ihm übermitteln, dass er daran interessiert sei, mit ihm , in Liebe und Freundschaft" zu sein und ständige Beziehungen herzustellen, „damit unsere Leute zugunsten unserer Freundschaft und Liebe, die zwischen uns sein werde, reisen und unseren Wohlstand sehen können". ${ }^{44}$ Es ist zu bemerken, dass die von den großfürstlichen Gesandten 1489 vorgestellte Instruktion noch keinen Hinweis auf den Abschluss eines Offensivpaktes gegen die Jagiellonen enthielt. Man kann mit Recht behaupten, dass diese Verhandlungen hauptsächlich auf die dynastische Eheschließung abzielten. Die Perspektive der engen Verwandtschaft mit der kaiserlichen Familie war dem Großfürsten zweifellos sehr erwünscht, weil sie seine Ansprüche auf „kaiserliche“ Würde noch nachdrücklicher begründet und ihm die Möglichkeit gegeben hätte, einen bemerkenswerten Platz im System der europäischen Mächte einzunehmen. Dabei ist nicht zu vergessen, dass er selbst nicht mit der Tochter, sondern mit der Nichte des byzantinischen Kaisers verheiratet war. Seine Botschafter waren beauftragt, dem Kaiser zu übermitteln, dass die von Poppel als die Ehemänner der Töchter des Großfürsten angebotenen Reichsfürsten vom Moskauer Herrscher wegen ihrer „Ungeeignetheit" (,neprigožestvo") abgelehnt wurden und dass nur der Sohn des Kaisers, d. h. der Römische König Maximilian selbst als möglicher Schwiegersohn des Großfürsten akzeptiert werden könnte. ${ }^{45}$

Die Verhandlungen mit ihnen führte der bekannte Diplomat und Spezialist für die nordeuropäischen Staaten Georg von Thurn (russ.: Jurij Delator), und diese Tatsache zeugt von einen bestimmten Interesse der Kaiserfamilie an dieser Allianz, die, wie es vielmals in der Fachliteratur

\footnotetext{
${ }^{42}$ WIMMER, Livland - ein Problem der habsburgisch-russischen Beziehungen (wie Anm. 31), S. 70.

${ }^{43}$ Lehmann, Chronica (wie Anm. 32), S. 999; PDS 1, Sp. 14-15.

${ }^{44}$ PDS I, Sp. 16-17.

45 PDS I, Sp. 17-18.
} 
erörtert wurde, gegen die Jagiellonen gerichtet war. Am 26. Juli 1489 hatte der Kaiser mit den russischen Verhandlungsführern ein besonderes $\mathrm{Ge}$ spräch, ${ }^{46}$ dessen Inhalt leider weder in den russischen noch in den deutschen Quellen überliefert ist. Da der Kaiser danach aber keine Botschaft mehr nach Moskau gesandt hat, kann man vermuten, dass er kein Interesse an der Angelegenheit mehr hatte; sein Gespräch mit den russischen Gesandten führte im übrigen auch nicht zu konkreten politischen Vereinbarungen.

Im Unterschied zu seinem Vater wollte Maximilian aber nicht auf die Kontakte mit dem Moskauer Herrscher verzichten; darum ließ er Georg von Thurn die großfürstliche Gesandtschaft nach Russland begleiten. Mit der Ankunft Thurns in Moskau (Juli -August 1490) beginnt die nächste Etappe der russisch-deutschen Verhandlungen im 15. Jahrhundert. Der Präliminarvertrag. den dieser Sendbote des Römischen Königs mitgebracht hatte, hetraf hauptsächlich die Militärhilfe, die Ivan III. Maximilian leisten sollte. Thurn interessierte sich besonders für die Möglichkeit, russische Militärkräfte nach Flandern gegen die „Verräter" Maximilians ebenso wie gegen den König von Frankreich zu schicken. ${ }^{47}$ Eigene Verpflichtungen gegenüber seinem russischen Verbündeten blieben unerwähnt. Die Absicht Maximilians, die Ressourcen des Moskauer Staates für die Lösung eigener Probleme auszunutzen (anders gesagt, sich Vorteile auf Kosten der anderen Seite zu verschaffen), zeigte sich offenbar schon in diesem Stadium der Verhandlungen; der Großfürst wich darum der an ihn gerichteten Bitte aus, um die ganze Aufmerksamkeit auf die Frage der dynastischen Ehe zu konzentrieren, ${ }^{48}$ die für ihn viel interessanter war als Kriegshandlungen auf der Seite Maximilians.

Die Verwandtschaft mit dem Sohn des Kaisers war dem Moskauer Großfürsten sehr erwünscht, weil er dadurch in den Kreis der einflussreichsten europäischen Herrscher aufgerückt wäre und auch die erhoffte Anerkennung seines „kaiserlichen“ („,cesarskij“) Status” erhalten hätte. Allerdings strebte Ivan III. wie immer danach, dem Partner die eigenen Spielregeln aufzuzwingen. Deshalb lehnte er Thurns Bitte ab, ihm die Braut zu zeigen und die Höhe der Mitgift zu besprechen; außerdem sollte seine Tochter im Falle der Eheschließung nicht gezwungen werden, katholisch zu werden. ${ }^{49}$ Zum Zeichen dafür, dass die Verlobung seiner Toch-

\footnotetext{
${ }^{46}$ Darüber erzählt Christoph Lehmann in seiner Chronik. LeHMANN, Chronica (wie Anm. 32), S. 999.

${ }^{47}$ PDS I. Sp. 30.

${ }^{48}$ Die Beratung der Bedingungen für die Eheschließung nimmt den größten Teil des Berichts über die Verhandlungen in Moskau 1490 ein: PDS I, Sp. 30-33.

${ }^{49}$ PDS I, Sp. 31.
} 
ter stattgefunden hatte und von großer Bedeutung war, verlieh er Thurn den Titel „Goldträger" (,zolotonosec") und ließ ihm prächtige Geschenke zukommen. ${ }^{50}$ Reiche Gaben waren auch für Maximilian bestimmt; damit demonstrierte der Großfürst seinen Wunsch, den Dialog mit ihm fortzusetzen.

Bezeichnend ist, dass der Großfürst entgegen den Gepflogenheiten dem Kaiser keine Geschenke und keinen Brief geschickt hatte. Etwas später, als Thurn ihn durch einen Sendboten danach fragte, erwiderte er, der Kaiser habe ihm nach dem Gespräch mit seinen Gesandten in Frankfurt, anders als sein Sohn, keine Botschaft geschickt; darum glaube er, dem Kaiser gegenüber nicht verpflichtet zu sein. ${ }^{51}$ Iwan III. fühlte sich so sehr beleidigt, dass er demonstrativ auf Geschenke von Nikolaus Poppel, der zwei Jahre zuvor als Gesandter Friedrichs III. nach Moskau gekommen war, verzichtete und seine Bitte ablehnte, dem Kaiser zum Geschenk zwei Elchpaare zu schicken. ${ }^{52}$

Nachdem die Präliminarverhandlungen über die Ehe mit dem Hause Habsburg beendet waren und Thurn Moskau verlassen hatte, hatte Ivan III. es eilig, vorbereitete Pläne umzusetzen. Um den Vertrag mit Maximilian abzuschließen, sandte er im November 1491 eine weitere Gesandtschaft mit Jurij Trachaniot und Vasilij Kulešin an der Spitze nach Deutschland. ${ }^{53}$ Das von ihnen mitgebrachte Vertragsprojekt, das nach dem Willen des Großfürsten konzipiert war, umfasste die konkreten Verpflichtungen, die beide Seiten gegen die gemeinsamen Feinde (die Jagiellonen), in Liebe, sowohl Brüderschaft, als auch Einigkeit“ übernehmen sollten. Ivan sollte Maximilian unterstijtzen, falls dieser beginnen sollte, „das Königreich von

${ }^{50}$ PDS 1, Sp. 34. Der Titel, zolotonosec“ und die mit ihm verbundene Verleihung der goldenen Kette mit Kreuz waren wohl eine der frühesten Formen der russischen Orden. Dazu Vladimir SoKolovsKIJ. Sergej B. BELECKIJ, Pskovskaja gramota XV v. iz archeologičeskich raskopok $\vee$ Tallinne (Eine Pskover Urkunde von den archeologischen Ausgrabungen in Tallinn), in: Pskov v rossijskoj i evropejskoj istorii, Moskau 2003, Bd. I, S. 138-142, hier S.141. Außer der Kette ließ Ivan III. an Thurn noch einen mit Hermelin gefütterten Mantel aus Atlas mit Gold und zwei Jagdspieße (,ostrogi“) aus vergoldetem Silber übergeben.

5) „Der Kaiser sandte zu unserem Herrscher keinen Botschafter und ließ auch nichts mündlich ausrichten, unser Herrscher braucht darum auch keinen eigenen Botschafter zum Kaiser zu senden, weil jener keinen Botschafter und keine Worte von sich zu unserem Herr geschickt hatte; wenn aber der Kaiser in Zukunft beginnt,, seine Botschafter zu unserem Herrscher zu schicken, wird unser Herrscher auch seine Botschafter zu ihm schicken“" („Ces $\left(\mu^{\prime \prime}\right.$ ' $k$ našemu Gosudarju svoego posla ne poslal, ni rečej $k$ nemu nenakazal ni kotorych, $i$ Gosudarju našemu ne bylo o čem posylati posla svoego k Cesarju, koli ego net posla, ni rečej $k$ našemu Gosudarju, a v pered učner Cesar' posylati k našemu Gosudarju svoich poslov, $i$ Gosudar' naš k nemu šlet svoich poslov"), PDS I, Sp. 58.

${ }^{52}$ PDS I, Sp. 52-58.

${ }^{53}$ Das Beglaubigungsschreiben dafür wurde schon am 16. August 1490 bestätigt. Hermann WIESFLECKER, Das älteste russische Originaldokument in Österreich? In: Mitteilungen des österreichischen Staatsarchivs (im folgenden: MÖSTA) 2, 1972, S. 141-150. 
Ungarn für sich zu erwerben" und in den Krieg gegen seinen Hauptrivalen, den böhmischen König Vladislav II. (aus der Dynastie der Jagiellonen), eintreten würde. Seinerseits rechnete der Großfürst mit der Unterstützung seines Verbündeten, wenn er mit Kiew um westrussische Länder kämpfen würde. ${ }^{54}$

Die Kontakte, die Ivan III. bereits in den 80er Jahren mit Ungarn und Serbien hergestellt hatte, erlaubten ihm, operativ nötige Informationen zu erhalten und dadurch die „Schmerzpunkte“ in der Außenpolitik Maximilians richtig zu bestimmen, um sie dann zum eigenen Vorteil auszunutzen. Der Tod des ungarischen Königs Matthias Corvinus (6.4.1490) führte zu dem erbitterten Kampf um die ungarische Krone zwischen Maximilian von Habsburg und Vladislav II. von Böhmen. Im Sommer 1490 hatte Maximilian Erfolge, aber wegen Geldmangels keine Möglichkeit, sie zu nutzen. Um sich die Hilfe der „Reichsstände“ zu sichern und von ihnen die benötigten Summen zu bekommen, berief Maximilian einen Reichstag nach Nürnberg. Am 22. März 1491 kamen die russischen Sendboten dorthin. Der von ihnen vorgelegte Vertrag ermöglichte es, die Beziehungen Ivans und Maximilians auf einer für beide Herrscher vorteilhaften Grundlage zu gestalten. Beide Herrscher sollten einander „hilfreich sein, wo und wie wir das vermögen", auf der Grundlage der Gegenseitigkeit, die für den Großfürsten sehr günstig war. Dies ist auch der Grund für die Annahme, dass der aus Byzanz entlehnte doppelköpfige Adler in dieser Zeit in das Wappen des Moskauer Großfürsten übernommen worden ist, um so die Ebenbürtigkeit der beiden Vertragspartner zu betonen. ${ }^{55}$ Maximilian, der auf die Hilfe seines Verbündeten angewiesen war, übernahm die ihm von Ivan III. angebotenen Spielregeln und nannte den Großfürsten sogar „mein Bruder". Am 23. Juni 1491 bestätigte er mit Eid (mit „Kreuzküssen“) den ausgehandelten Vertrag, obwohl der Punkt über das Ehebündnis wegen der Verlobung Maximilians mit Anna von der Bretagne seine Bedeutung verloren hatte.

Die Dynamik der Entwicklung der deutsch-russischen Diplomatie wirkte sich unmittelbar auf die Lage in der baltischen Region aus und bestimmte die Position, die Großfürst Ivan III. bezüglich der Hanse und der Anwesenheit der Hansen in seinem „Vatererbe" Groß-Novgorod einnahm, ebenso wie in Bezug auf Livland, das immer die Rolle eines Vermittlers im Handel der hansischen Städte mit der Ruś spielte. Der Abschluss des Handelsvertrages von 1487 eröffnete den Zeitraum, in dem seitens der russischen Verwaltung günstige Bedingungen für den hansischen Handel

\footnotetext{
st PDS I, Sp. 37-38.

${ }^{55}$ Natalija A. SObOleva, Vladimir A. Artamonov, Simvoly Rossii (Russlands Symbole), Moskau 1993, S. 23.
} 
in Russland geschaffen wurden. Das geschah freilich nicht ohne Widerstände. Im Jahre 1488 schränkten die Novgoroder die hansischen Vorrechte im Pelz-, Wachs- und Honighandel kräftig ein. Lübeck als Haupt der Hanse bemühte sich, die Hindernisse zu beseitigen, und versuchte damals die Gelegenheit zu nutzen, um die Abstellung der Beschwerden der Hansen in Novgorod erreichen. Damit wandten sich die Städte an die großfürstlichen Gesandten, die 1489 auf dem Weg nach Russland in die Stadt gekommen waren. Diese versprachen ihrerseits, bei der Lösung des Problems behilflich zu sein und zwischen der Hanse und den Novgoroder Statthaltern zu vermitteln. ${ }^{56}$

Dabei darf nicht außer acht gelassen werden, dass der Großfürst selbst damals eine den Hansen gegenüber freundliche Haltung einnahm. Im Frühjahr 1489 empfing er gnädig die hansische Gesandtschaft mit dem sog. Hofknecht des Peterhofs an der Spitze und versprach ihr, im Sommer nach Novgorod zu kommen und dort die Beschwerden zu untersuchen. ${ }^{57}$ Dabei achtete der Großfürst sogar nicht auf das provozierende und verschiedentlich für ihn beleidigende Verhalten Revals. ${ }^{58}$ Im Spätherbst 1491 begannen die Verhandlungen über die Verlängerung eines Friedensvertrags zwischen dem Moskauer Staat und dem livländischen Orden; diese Vereinbarung ist, wenn man die Rolle des Ordens selbst und seiner Meister im politischen Leben Livlands erwägt, als ein vollwertiger zwischenstaatlicher Vertrag zu bewerten, bei dem die russische Seite initiativ wurde. ${ }^{59}$

Das Wohlwollen, das der Großfürst sowohl gegenüber der Hanse als auch gegenüber Livland an der Wende der 1480er zu den 90er Jahren zeigte, kann man kaum durch seine Absicht erklären, die Wirtschaft zu entwickeln und die Handelsverbindungen auszuweiten, da weder er noch seine nächsten Nachfolger auf dem Moskauer Thron eine solche „Beziehung zur Wirtschaft" hatten, die im 16. und 17. Jahrhundert in Europa alle wesentlichen Formen des Protektionismus bewirkte. Das Problem sollte dagegen unter ganz anderen Aspekten untersucht werden.

\footnotetext{
${ }^{56}$ Briefe, die damals von den Stadträten und Gesandten an den Großfürsten geschrieben wurden: HUB 11, 296, 297: HR III, 2, 264, 265. Daraus kann man sehen, dass Lübeck und die Gesandten die Beschwerden der Hansen in Novgorod über den Salz- und Honighandel intensiv besprochen haben.

${ }^{57}$ HUB 11, 276, 277, 279; HR III, 2, 258.

${ }^{58}$ Die Revaler hielten es im April 1489 für richtig, dass alle deutschen Kaufleute in Novgorod, solange der Großfürst seine Versprechen nicht erfüllen und die Beschwerden nicht abstellen würde, den Peterhof mit ihren Waren verlassen sollten (HUB 11, 289). Im Spätsommer, als in Novgorod das sog. Wägegeld erhöht wurde. antwortete Reval mit derselben Maßnahme bezüglich der Russen in der Stadt, wo sich damals ein beträchtlicher Besitz des Großfürsten selbst befand (HUB 11, 315).

${ }^{59}$ HUB 11,509 .
} 
Erstens: Die wendischen Hansestädte gehörten zum Reich; was Livland angeht, wurde schon während der Verhandlungen mit Poppel 1489 betont, dass die in Livland wohnenden Deutschen (,nemcy Viflandskej zemli" Untertanen des Kaisers und Livland ein Reichsgebiet waren. Die Russen widersprachen dem nicht, weil sie sich mit dieser Auffassung schon abgefunden hatten, obwohl diese Vorstellung der Realität nicht entsprach. ${ }^{60}$ Auf keinen Fall wollte der Großfürst im Verlauf der Verhandlungen zu einem für ihn so wichtigen Zeitpunkt Spannungen mit Reichsangehörigen heraufbeschwören.

Zweitens: Der hansische Handel versorgte den Moskauer Staat mit Metallen, vor allem mit Buntmetall, das für die Aufrüstung benötigt wurde, ${ }^{61}$ und mit Pferden, ${ }^{62}$ ohne die die Ausrüstung der russischen Adelskavallerie schwierig gewesen wäre. Da Ivan III. in dieser Zeit den Kampf gegen Litauen führte und sich auf den Krieg gegen Schweden vorbereitete, musste er die ununterbrochene Lieferung solcher Waren sicherstellen.

Drittens: Der Deutsche Orden in Livland, der in der sowjetischen Geschichtsschreibung meistens als feindlicher und aggressiver Nachbar Russlands wahrgenommen wurde, hatte in diesem konkreten Zeitraum Interesse an einem Frieden mit dem Moskauer Staat. Deshalb trat der Orden in Livland mit dem Ordensmeister Johann Freitag von Loringhoven an der Spitze „im Kielwasser Habsburgs in eine (dauerhafte) Allianz" mit Moskau ein. ${ }^{63}$ Kaiser Friedrich III. wie auch sein Sohn beabsichtigten, den Deutschen Orden einschließlich seines livländischen Zweiges im Kampf gegen den polnischen König aktiv auszunützen. ${ }^{64}$ Der Volksmund sagt: Der Feind meines Feindes ist mein Freund. Dieser Logik folgend, musste also der livländische Orden vom Großfürsten von Moskau eher als Verbündeter denn als Gegner behandelt werden.

Viertens: Seit den 1470er Jahren bemühten sich die Livländer und die Hanse, die Moskauer Herrscher für sich zu gewinnen, und deswegen er-

${ }^{60} \mathrm{Vgl}$. die Forschungen von M. Hellmann, die beweisen, dass Livland nie Teil des deutschen Königreiches war. Manfred HellmanN, Altlivland und das Reich, in: Felder und Vorfelder russischer Geschichte. Studien zu Ehren von Peter Scheibert, Freiburg 1985 , S. 61-75, hier S. 71.

${ }^{61}$ Die russischen Länder benötigten Metalllieferung aus dem Ausland bis zum 17. Jahrhundert. CHORošKEvič, Torgovlja Velikogo Novgoroda (wie Anm. 1), S. 307. 309. Metalle und Metallwaren bildeten eine der wichtigsten Gruppen des hansischen Imports nach Novgorod. Flisaheth HARDER-GERSDORFF, Hansische Handelsgüter auf dem Großmarkt Novgorod (13.-17. Jh.): Grundstrukturen und Forschungensfragen, in: Novgorod: Markt und Kontor der Hanse (wie Anm. 1), S. 133-151, hier S. 135.

${ }^{62}$ Es geht hier um die Kriegspferde, die aus Livland geliefert und in Russland hoch geschätzt wurden. CHORoŠKEvıČ, Torgovlja Velikogo Novgoroda (wie Anm. 1), S. 322-323.

${ }^{63}$ WIMMER, Livland - ein Problem der habsburgisch-russischen Beziehungen (wie Anm. 31), S. 72.

${ }^{64}$ Biskup, Der Deutsche Orden im Banne der habsburgischen Politik (wie Anm. 41). 
kannten sie nicht nur Ivan III., sondern auch seinen Sohn Ivan den Jungen als „Zaren“ bzw. „Großen Herren“ an. ${ }^{65}$ Diese Tatsache war, wie schon gesagt, für Ivan III. von großer Bedeutung.

Und endlich, auf dem Weg Novgorod-Narva-Reval-Lübeck fuhren die russischen und deutschen Gesandten, die auf diese Weise die gefährliche Marschroute durch die den Jagiellonen gehörenden Länder vermeiden wollten. Den livländischen und hansischen Quellen zufolge hatten die Botschafter auf diesem Weg freie Fahrt. Wenn der Großfürst seine Sendboten nach Deutschland schickte, übergab er ihnen jedes Mal Briefe und Geschenke für die Räte der Hansestädte, damit sie ihnen den gefahrlosen und bequemen Weg gewährleisten sollten. ${ }^{66}$

Obwohl die Hanse und der Peterhof in Novgorod bei den Verhandlungen Ivans III. mit Maximilian offenbar nicht erwähnt, Livland und der Orden nur als Nebenthemen berührt wurden, standen sie immer im Hintergrund dieser Verhandlungen. Das lässt sich damit erklären, dass sie dem Moskauer Großfürsten die Möglichkeit boten, den Untertanen des Reichs gegenüber Respekt zu zeigen und damit bei den Herrschern eine positive Einstellung hervorzurufen. Außerdem trug die gute Behandlung Livlands und der Hansestädte durch den Moskauer Herrscher zu dem ununterbrochenen Austausch von Gesandtschaften zwischen Russland und Deutschland bei und stellte Ivan einige dringend benötigte Importwaren zur Verfügung. Es konnte also eine positive Wirkung auf die Entwicklung ihrer gegenseitigen Kontakte ausüben, wenn die Beziehungen zwischen Maximilian und Ivan III. unbelastet blieben.

Der Bruch zeigte sich Anfang 1492, als man in Moskau erkannte, dass Maximilian am 7. November 1491 den Friedensvertrag mit Vladislav II. von Böhmen in Preßburg abgeschlossen und diesem die ungarische Krone überlassen hatte, gegen die Rückgabe einiger erbländischer Besitzungen in Österreich, solide Kontributionszahlungen und den Anspruch auf den ungarischen Thron für den Fall, dass Vladislav ohne männlichen Erben sterben sollte.

Damals befand sich Georg von Thurn in Moskau, der dort bereits am 20. November 1491 angekommen war, um im Namen Maximilians den Vertrag beim Großfürsten zu bestätigen. Der Fürsı küsste das große Kreuz, er hatte die Absicht, seine Bündnisverpflichtungen zu erfüllen und in den Krieg gegen Litauen zu einzutreten, ${ }^{67}$ obwohl der Vertrag von Preßburg das Offensivbündnis mit Ivan III. gegenstandslos machte. Dass Thurn keine Vorstellung von den politischen Absichten seines Herrschers hatte und

\footnotetext{
${ }^{65}$ CHORošKevič, Rossija v sisteme meždunarodnych otnošenij (wie Anm. 22), S. 102.

${ }^{66}$ PDS I. Sp. 20-24, 59-61, 86-87.

${ }^{67}$ PDS I, Sp. 79-80.
} 
von dem Friedensschluss mit Vladislav nichts wusste, erscheint wenig wahrscheinlich. Leider fehlt eine Instruktion, die ihm von Maximilian vor seiner Abreise nach Moskau mitgegeben wurde, aber es gibt einen Geleitbrief für Thurn mit der Beschreibung seiner Reiseroute nach Moskau, der vielleicht Licht auf seine Mission im Jahre 1492 werfen kann. Nach diesem Dokument besuchte dieser Botschafter Maximilians den Herrscher von Schweden Sten Sture, die Räte von Lübeck, Reval und Riga, den Erzbischof von Riga, den Bischof von Reval, den Hochmeister Johann von Tiefen, den livländischen Ordensmeister Johann Freitag und dessen Landmarschall Wolter von Plettenberg. ${ }^{68}$ Mit Hilfe der russischen Gesandtschaftsbücher lässt sich, wenigstens teilweise, das Ziel seiner Reise erklären.

Die Gesandtschaftsbücher zeugen von dem hohen Kenntnisgrad der Moskauer Machthaber über die politische Situation in der baltischen Region; das war zweifellos eine Folge der in den zurückliegenden Jahren aufgebauten Verbindungen des Moskauer Staates mit Europa. Man wusste, dass Maximilian Ansprüche auf Danzig, Thorn und andere preußische Städte erhob, die sich 1454 unter die Herrschaft des polnischen Königs gestellt hatten. Die Gesandtschaftsbücher enthalten eine Mitteilung darüber, dass Thurn zu diesem Vorhaben den Bischof von Reval („Kolywań“) besuchen und bitten sollte, auf den Hochmeister des Deutschen Ordens, Johann von Tiefen, dahingehend einzuwirken, dass dieser den Frieden von Thorn 1466, der den Orden in die Abhängigkeit von der polnischen Krone gebracht hatte, aufkündigen und den Krieg gegen den König von Polen erklären sollte. Darüber hinaus wandte sich Maximilian durch die Vermittlung Thurns an Ivan III. und schlug ihm vor, dem Deutschen Orden in Preußen und Livland wie auch Danzig. Thorn und anderen Städten Schutz und Schirm zu gewähren (,prinjati v svoe sobljudene $e^{6)}$. ${ }^{69}$ Der Sinn dieses Vorschlags ist schwer zu verstehen, weil die diesbezüglichen deutschsprachigen Dokumente völlig fehlen und Thurns Worte in der russischen Nacherzählung sehr unklar sind.

Es ging dabei weniger um die Unterordnung der beiden Deutschordenszweige unter den Großfürsten, sondern nur um eine an Ivan III. gerichtete Bitte, sich im bevorstehenden Kampf gegen Polen auf die Seite des Ordens zu stellen. Davon zeugen die gleichzeitige Erwähnung Danzigs und Thorns - der Großfürst erhob selbst Ansprüche auf sie, hätte sie sich aber unter keinen Umständen unterordnen können - wie auch der Vorschlag, die territorialen Auseinandersetzungen zwischen den russischen Ländern

${ }^{68}$ BAZILEVIČ. Vnešnjaja politika Russkogo centralizovannogo gosudarstva (wie Anm. 13), S. 272.

${ }^{69}$ PDS I, Sp. 74-75. 
und dem livländischen Orden im Laufe der zweiseitigen Verhandlungen beizulegen. Im Falle der Unterordnung des Ordens unter den Großfürsten wäre derartiges gar nicht nötig gewesen.

In dieser Angelegenheit wiederholte Thurn die schon von Poppel 1489 vorgetragene Ansicht, wonach die Ordensmeister in Preußen und in Livland als Untertanen (,podderžavniki“) des Kaisers zu gelten hätten und Livland als „das Land des Römischen Reichs und meines Herrschers". Außerdem äußerte er die Hoffnung, dass der Großfürst von Moskau an seinen Staat neue Länder anschließen würde, ohne auf „das Land unserer Gottesmutter" einen Anschlag zu machen. ${ }^{70}$ Der Vorschlag Maximilians fiel in dieselbe Zeit, in der die Verhandlungen zwischen dem Großfürsten und dem Meister des livländischen Ordenszweiges Freitag von Loringhoven über die Erneuerung des russisch-livländischen Friedens geführt wurden. In diesem Zusammenhang war der Status des dem Meister unterstellten Ordensstaates von großcr Bedeutung. Livland als Reichslehen passte Ivan III. freilich nicht; deshalb ließ er sich nur darauf ein, beide Meister in seinen Schutz zu nehmen, wenn sie ihm „čelom biti" leisten, d. h. sich verneigen würden. Dabei ist darauf hinzuweisen, dass das „čelobit' $e^{\prime \prime}$ in Russland ein unbestreitbares Zeichen von Abhängigkeit war, ${ }^{71}$ deshalb der beharrliche Wunsch des Großfürsten, eine solche Formulierung durchzusetzen, ${ }^{72}$ die die Stärkung seiner Stellung in Preußen und in Livland bedeuten konnte. Die Lösung dieser Frage verzögerte zweifellos die Verhandlungen über die Verlängerung des Friedensvertrages zwischen dem Moskauer Staat und dem livländischen Orden, der erst im März 1493 unterschrieben wurde.

Ergänzend wäre anzumerken, dass Thurn bei seinen Bemühungen, Ivan III. auf die Seite Maximilian zu ziehen, einen ernsthaften Fehlgriff tat. Er schlug dem Großfürsten vor, an einem Tag in Königsberg teilzunehmen, auf dem die Vertreter des Ordens, der Bischöfe und der Städte eine Entscheidung über die Bildung der antipolnischen Koalition treffen würden. ${ }^{73}$ Dieser Vorschlag berührte das Ehrgefühl des Herrschers, der meinte, Gott selbst habe ihm eine unbeschränkte Macht verliehen, und darum jeden konkurrierenden Machtanspruch als das schwerste Verbrechen bewertete. Er hatte kein Verständnis für die Erarbeitung kollegialer Beschlüsse, da er

\footnotetext{
${ }^{70}$ „krome togo mesta prečistyja Gospožce našej", PDS I, Sp. 78.

7 PDS I, Sp. 80-82.

${ }^{72}$ Ekaterina R. SkvajRS, Svetlana N. FERdinand, Ganza i Novgorod: jazykovye aspekty istoričeskich kontaktov (Die Hanse und Novgorod: sprachliche Aspekte der historischen Kontakte). Moskau 20(12. S. 234-239. Nicht zufällig ist, dass Thurn den Grobfürsten vergebens darum ersuchte, die Anrede der Ordensmeister an ihn nicht als ,celobit"e", sondern als Bitte aufzufassen.

${ }^{73}$ PDS I, Sp. 78.
} 
sich selbst bei der Regierung des Staates nur nach dem eigenen Willen richtete, den er als von oben gelenkt wahrnahm. Es verwundert darum nicht, dass er auf die Vorschläge Thurns überhaupt nicht einging.

Als Maximilian seinem russischen Verbündeten vorschlug, sich von der Gegnerschaft gegen Litauen loszusagen und in den Kampf mit Polen als einfaches Mitglied der Allianz unter der Führung von Habsburg einzutreten, verletzte er unabsichtlich den Großfürsten, dessen Ehre von der Ablehnung seines Eheprojekts schon vorher gekränkt worden war. Zeichen dieser Unzufriedenheit kann man schon seit Frühling 1492 in seinem sich verändernden Verhältnis zum Hansehandel beobachten, dessen Symbol für jeden russischen Menschen des 15. Jahrhunderts der St. Peterhof in Groß-Novgorod war, und zu Livland, da gerade die livländischen Kaufleute alle Fäden des hansischen Handels mit den russischen Ländern in ihren Händen hielten. Vor allem zeigte sich, dass die Verlängerung des Vertrages zwischen dem livländischen Orden und Novgorod gefährdet war, da der Großfürst eine Reihe von Forderungen vorgebracht hatte. die gemäß den Bedingungen des Handelsvertrages von 1487 nicht vorgesehen waren. Freitag von Loringhoven, dem es in den Jahren 1485 bis 1492 gelang, den Frieden mit Moskau zu festigen, war vor allem bestrebt, den Moskauer Herrscher zu einer livlandfreundlichen Politik zu bewegen und sprach sich deshalb für die Erfüllung der vom Großfürsten gestellten Forderungen aus. ${ }^{74}$ Diese schienen ihm weniger gravierend zu sein; der Revaler Rat aber weigerte sich, Zugeständnisse zu machen. ${ }^{75}$ Die Bestätigung des Friedens verzögerte sich darauthin bis zum März des nächsten Jahres.

Im Frühling 1492 begann man auch mit dem Bau der Festung Ivangorod am Fluss Narova, die auf Kanonenschussweite vom Ordensschloss Narva entfernt war. Die Gründung eines russischen Hafens sollte den direkten Handelskontakten mit West-Europa dienen. Der Bau von „galleen“, die in den hansischen Quellen erwähnt werden. ${ }^{76}$ war jedoch nicht gleichbedeutend mit dem Aufbau einer Flotte. In Ivangorod wurden wohl russische Flussboote (Lodien) gebaut, über die der Vogt von Narva dem Ordensmeister von Zeit zu Zeit berichtete. ${ }^{77}$ Hätte man aber bei der Stadt einen ernsthaften Schiffbau betrieben, hätten der Vogt von Narva wie auch der Stadtrat das in ihren Berichten vermerkt, zumal man alles im ,neuen russischen Schloss" Geschehende von den Mauern von Narva aus beobachten konnte. Im Jahre 1492 jedoch erregte nur eine Tatsache die Livländer, nämlich die Errichtung einer neuen starken Festung in der Nähe

\footnotetext{
${ }^{74}$ HUB $11,582$.

${ }^{75}$ Ebd.

${ }^{76}$ HUB 11, 739.

${ }^{77}$ LEKUB II, 2, 270, 283, etc.
} 
Narvas. ${ }^{78}$ Ihr Bau war durch keine Kriegsgefahr erforderlich geworden, weil der livländische Orden sich seit 1485 mit ganzer Kraft darum bemühte, den Frieden mit dem Moskauer Staat zu erhalten. Es ist daran zu errinern, dass beide Staaten damals über eine Friedensverlängerung verhandelten und der Ordensmeister Freitag sich dabei, wie oben gesagt wurde, bemühte, der russischen Seite ständig nachzugeben. Nichtsdestoweniger wurde die Festung in kürzester Zeit, nämlich im Lauf einer einzigen Bausaison, wie bei einer realen Kriegsgefahr, beendet; die Eile führte dazu, dass sie nur schwach befestigt und schlecht ausgestattet war. ${ }^{79}$ Diese Tatsache wie auch die Lage der Festung - in Sichtweite von Narva (jeder, der irgendwann in Narva gewesen ist, kann sich dies gut vorstellen) - legt die Vermutung von dem demonstrativen Charakter ihres Baues nahe, der, wir wiederholen das noch einmal, bald nach der oben angeführten, für die russische Seite unangenehmen Veränderung im Verlauf der russisch-habsburgischen Verhandlungen begonnen worden war. Es ist darum kein Zufall, dass der Großfürst unter anderen Anordnungen, die er im Herbst 1492 seinen nach Deutschland abreisenden Botschaftern erteilte, ihnen befahl, sich kundig zu machen, welchen Eindruck der Bau Ivangorods und die Verschärfung der Handelsbedingungen in Novgorod in Narva und Reval erweckt hatten. ${ }^{80}$ Es ist außerdem bekannt, dass sich die Lage an der russisch-livländischen Grenze mit dem Bau Ivangorods erheblich verschlechterte. $^{81}$

Im Herbst 1492 entsandte Ivan III. noch einmal eine Gesandtschaft nach Deutschland mit Jurij Trachaniot und Michail Kljapik-Eropkin an der Spitze. Das war sein letzter Versuch, ein Interesse an der Vereinbarung mit Moskau bei Maximilian zu wecken, weil es für den Großfürsten nicht wünschenswert war, die so glänzende Aussicht, die ihm das Bündnis mit Habsburg gab, leichtfertig aufzugeben. Den Inhalt der Instruktion, die dabei der Großfürst seinen Botschaftern gegeben hatte, bezeugt dies sehr beredt. Sie sollten die letzten Nachrichten über die habsburgisch-jagiellonischen Beziehungen sammeln, damit der Großfürst sich über die Ansprüche Maximilians ein genaues Bild machen könnte. Falls es zutraf, dass

${ }^{78}$ Rossijskij gosudarstvennyj archiv drevnich aktov (im folgenden: RGADA), f. 147, op. I, ¿. 2, Nr. 547, 548.

${ }^{79}$ Der Vogt berichtete dem Ordensmeister Plettenberg im Spätsommer: „Sie (die Russen) haben keine Wehre darin gebaut, noch Holzwerk, von dem man Büchssen abschießen mag. was mich sehr verwundert. Man könnte das Schloß ohne Schwertschlag einnehmen. Jeder Deutsche kann hinauf, denn da sind nur Leute, welche Steine brechen und Kalk brennen [...]. Auch sind im Innern noch keine Schornsteine oder Kammern“, d. h. keine Bedingungen für das Überwintern, RGADA, f. 147, op. 1, č. 2, Nr. 548.

${ }^{80}$ PDS I, Sp. 101.

${ }^{8 I}$ SELART, Zur Sozialgeschichte der Ordensgrenze Estlands (wie Anm. 40), S. 540-541. 
diese Beziehungen gebrochen würden, sollten sie ihn der russischen Bündnistreue versichern. Es sollte auch versucht werden, die Heiratsverhandlungen wieder aufzunehmen und „die bretonische Ehe“ Maximilians zu annullieren. ${ }^{82}$

Am 15. Januar 1493 kamen die Gesandten nach Colmar, bald danach traf dort auch Maximilian ein. Die Information über das Gespräch zwischen ihnen ist in den russischen Gesandtschaftsbüchern äußerst dürftig, sie kann aber durch die Angaben eines im Wiener Haus-, Hof- und Staatsarchiv erhaltenen Schriftstücks ergänzt werden. Es handelt sich dabei um die in dialogische Form gebrachte Aufzeichnung dieses Gesprächs, die wohl von einem deutschen Beamten gemacht wurde. Die Botschafter teilten, wie es ihnen vorgeschrieben worden war, Maximilian den Wunsch des Großfürsten mit, dem König zu helfen, wenn er „sein Vatererbe Ungarn“ zurückgewinnen wolle. Maximilians Antwort ließ wenig Hoffnung auf einen Erfolg, zumal er behauptete, er wäre gezwungen, den Krieg gegen Frankreich aufzunehmen und darum den Plan eines Krieges gegen Vladislav II. zurückstellen müsse (in den Gesandtschaftsbüchern heißt es in diesem Zusammenhang, der Römische König wolle „Ungarn im ungesetzlichen Besitz" lassen). Das Gespräch verlief allem Anschein nach in einer sehr gespannten Atmosphäre, worüber Maximilian sehr unzufrieden war und sogar Einspruch gegen den von den russischen Gesandten angeschlagenen Ton erhob. Am Ende des Gespräches wiederholte er noch einmal, dass er nicht mehr beabsichtige, das Blut von Christen zu vergießen, versuchte dabei aber, den Großfürsten in eine Allianz gegen die Türken einzubeziehen. ${ }^{83}$ Nach seinen Plänen. sollte der neue Großfürst von Litauen Alexander in diesen Verbund eintreten, mit dem sich Ivan damals aber im Krieg befand, so dass der Vorschlag Maximilians für ihn gänzlich unannehmbar war.

Im Frühling 1494 kehrte die russische Gesandtschaft heim. Vielleicht hoffte Maximilian damals noch, den Moskauer Staat zum Kampf gegen die Türken zu gewinnen, und beabsichtigte darum, eine neue Gesandtschaft nach Moskau zu schicken, ${ }^{84}$ aber diese kam wohl nicht zustande. Maximilians Ehe mit Bianca Sforza ${ }^{85}$ wie auch sein früheres Bündnis mit

\footnotetext{
${ }^{82}$ PDS 1, Sp. 89-92.

${ }^{83}$ HHSA, Russica, fasc. Ia, fol. 2-7.

${ }^{84}$ Am 8. April 1494 unterzeichnete Maximilian einen Geleitbrief für den Grafen Willhelm von Zagoria und Bartholomäus von Modrusch, die beauftragt wurden. als seine Gesandten nach Moskau zu fahren. HHSA, Maximiliana, fasc. 2a. fol. 352.

${ }^{85}$ Die russischen Botschafter in Mailand weigerten sich. der Hochzeit Maximilians mit Bianca Sforza beizuwohnen. Dazu M. D. BuTurl.s. Bumagi Florentijskogo gosudarstvennogo archiva, kasajuščiesja do Rossii (Schriftstücke aus dem Staatsarchiv zu Florenz bezüglich Russlands), Bd. 2, Moskau 1874, S. 277.
} 
Vladislav II. zeigten dem Großfürsten ganz klar, dass eine Allianz mit Maximilian für ihn völlig aussichtslos war. Das ist nicht verwunderlich, weil die politischen Prioritäten der beiden Herrscher so geartet waren, dass keiner dem Hauptziel des anderen dienen konnte. Es war klar, dass sich die Beziehungen zwischen dem Großfürsten von Moskau und dem Römischen König nicht zu stärker institutionalisierten staatlichen Beziehungen entwickeln und dementsprechend keine reale politische und militärische Bedeutung erlangen konnten. Ihre Gegnerschaft zu den Jagiellonen hatte sie einander angenähert, doch nur für kurze Zeit; als sich das Interesse Maximilians hauptsächlich auf einen Krieg gegen den König von Frankreich gerichtet und Ivan III. darauf verzichtet hatte, seiner Politik in Bezug auf den Deutschen Orden und auf die Türken Rechnung zu tragen, verlor er den Wunsch, mit dem Moskauer Großfürsten zu verhandeln. Die diplomatischen Beziehungen zwischen ihnen wurden erst in der Regierungszeit Vasilijs III. (1505-1533) wiederhergestellt. ${ }^{86}$

Der Misserfolg der Verhandlungen mit dem Reich bedeutete für Ivan eine schmerzliche Niederlage. Der Großfürst hatte auf die Verhandlungen der Jahre 1489 bis 1493 viel Energie und hohe Kosten verwandt, weil er auf die Herstellung enger, paritätischer wie auch durch eine dynastische Ehe befestigter Beziehungen mit einem Angehörigen der kaiserlichen Familie gehofft hatte, die seine Ansprüche auf eine besondere Machtstellung bekräftigen konnten. Sein Hauptgegner, der Großfürst Alexander von Litauen, zögerte nicht, die Schwächung der Stellung Ivans zu betonen. Im Text des russisch-litauischen Friedensvertrages von 1494 wurde dieser nur "Großfürst", ohne den Zusatz „Großer Herrscher" genannt. ${ }^{87}$

Das Wohlwollen Ivans III. der Hanse. Livland und dem Novgoroder Hansekontor gegenüber war damit zu Ende. Die Beziehungen der Hanse mit Novgorod, die sich während der Jahre zuvor verbessert oder wenigstens nicht verschlechtert hatten, ${ }^{88}$ wurden seit Ende 1493 durch neue Gegensätze erschwert. Bereits im Dezember 1493 hatte man in Novgorod neue Einschränkungen hinsichtlich des Prüfens und Wiegens der hansischen Waren eingeführt; infolgedessen fassten die livländischen Städte den Beschluss, sich an den Großfürsten zu wenden, damit er die Ursache ihrer Auseinandersetzungen mit Novgorod beseitigen ließe. ${ }^{89}$ Im Verlauf der vergangenen Jahre hatten sich dic Hansen in Deutschland und Livland

\footnotetext{
${ }^{86}$ WIMMER, Livland - ein Problem der Habsburgisch-russischen Beziehungen (wie Anm. 32), S. 68-83.

${ }^{87}$ Diese Anrede wurde in den litauischen Urkunden von 1494 bis 1499 verwandt. CHOROŠKEVIČ. Rossija v sisteme meždunarodnych otnošenij (wie Anm. 22), S. 101-102.

${ }^{88}$ Tiberg, Moskau, Livland und die Hanse (wie Anm. I6), S. 28.

${ }^{89}$ LEKUB II, 1, 12, 14, 19.
} 
an das Wohlwollen des Moskauer Herrschers gewöhnt und fuhren fort, die Schuld an Behinderungen ihres Handels nicht ihm, sondern den Machthabern in Novgorod zu geben. Daraus entstand der Gedanke, eine Gesandtschaft der livländischen Städte nach Moskau zu entsenden, der vom Hansetag zu Bremen am 25. Mai 1494 gebilligt wurde. ${ }^{\left.{ }^{\prime \prime}\right)}$ Als Resultat zogen die Ratsherren Remmelingrode und Schrowe nach Moskau. ${ }^{9 !}$

Der Rat von Reval nutzte dabei den Aufenthalt der aus Italien heimkehrenden Gesandten des Großfürsten, Manuil und Daniil (Ralevy), indem er ihnen eine Beschwerde der Bürgerschaft an ihren Herrscher mitgab. Aus Gründen ihrer langen Abwesenheit hatten diese vielleicht wenig Kenntnis von der veränderten Lage und waren darum einverstanden, diesen Auftrag zu erfüllen. ${ }^{92}$ Es ist daran zu erinnern, dass die Botschafter der Großfürsten seit 1489 ständig als Vermittler zwischen der Hanse und dem Moskauer Großfürsten auftraten, weshalb Manuil und Daniil auch keinen Grund für eine Absage hatten. Als sie aber in Novgorod angekommen waren und entsprechende Nachrichten erhalten hatten, änderte sich ihr Verhalten so offenkundig, dass ein junger Revaler, der sie begleiten sollte, sich gezwungen sah, heimlich heimzukehren. Er hatte Angst, er könnte gewaltsam nach Moskau gebracht werden..$^{93}$ Die Gesandten erhoben in der Folgezeit Anklage gegen Reval wegen ihnen in der Stadt zugefügten Unrechts, was das Schicksal des Novgoroder Hansekontors verhängnisvoll beeinflusste.

Die Reise der livländischen Sendeboten Remmelingrode und Schrowe nach Moskau Ende Sommer 1494 wurde zum Auftakt für die Schließung des Kontors. Sie wurden schon unterwegs gefangen genommen; man ließ sie lange nicht aus Novgorod abreisen und nahm ihnen ihre Papiere, ${ }^{94}$ um sie vielleicht dem Großfürsten zuzustellen. In Moskau wurden sie allerdings vom Großfürsten gnädig empfangen, aber die großfürstlichen Beamten zogen offensichtlich die Verhandlungen in die Länge ${ }^{95}$, was bei der Vorbereitung großer Aktionen üblich war. Nach Ansicht Remmelingrodes beabsichtigte der Großfürst bereits zu dieser Zeit die

\footnotetext{
${ }^{90}$ HR III, 3, $353 \$ 74,75,92$.

${ }^{91}$ HR III. 3, 331, 332; HUB 11, 733, 734, 737, 739, 746; LEKUB II. 1, 12, 19, 23.

${ }^{92}$ HR III. 2, 267; HUB 11, 737; LEKUB 11, 1, 10.

${ }_{93}^{93}$ HUB 11, 746; LEKUB II, 1, 10, 12.

${ }^{94}$ Der Brief von Schrowe in: LEKUB II, 1, 34; der Brief von Remmelingrode in: LEKUB II, 1, 95 .

${ }^{95}$ Die Gesandten kamen in Moskau am 18. September an. 15 Tage lang warteten sie auf eine Audienz beim Großfürsten, dann hatten sie Gespräche mit den großfürstlichen Beauftragten und noch ein Treffen mit Ivan IIl. (6.10.1494), bei dem sie die Erlaubnis bekamen heimzukehren. Aber sie warteten noch weitere 10 Tage auf die Geleitbriefe. Vgl. den Brief von Schrowe in: LEKUB II, 1, 34.
} 
Verhaftung der Hansen in Novgorod. ${ }^{96}$ Es ist zu vermuten, dass die Kränkungen, die den russischen Botschaftern in Reval zugefügt worden waren, als hauptsächliche Erklärung für das Vorgehen in Novgorod dienen konnten, aber dank des Handelns von Remmelingrode, der das von ihm geforderte Strafgeld rechtzeitig auftreiben konnte, trat diese Variante in den Hintergrund und überließ ihre Stelle der anderen, in der es um die Todesstrafen an zwei Russen in Reval ging. ${ }^{97}$ Diese waren, wie das vor kurzem Selart bewiesen hat, ,für die großfürstliche Diplomatie ein passender Vorwand und kein wirklicher Grund".98

Es steht heute fest, dass die Handelsentwicklung in Novgorod sehr stark von der politischen Situation abhängig war, und die hier erörterten Ereignisse von 1494 bestätigen dies noch einmal. Nach Nikolaj Borisov waren die Schließung des Novgoroder Kontors und die Verhaftung seiner Bewohner ein „zweifelhaftes Unternehmen“, das keinen ökonomischen und politischen Sinn hatte. ${ }^{99}$ Der Großfürst hatte den Kampf mit Litauen noch nicht beendet, bereitete sich auf den Krieg gegen Schweden vor und schuf nun an der Grenze im Nordwesten noch einen Konfliktherd; damit fügte er dem Außenhandel des Moskauer Staates Schaden zu und entzog seinem Land einen erheblichen Teil der Metall-, Ausrüstungs- und Pferdelieferungen. Nur unter außergewöhnlichen Umständen konnte sich der Großfürst zu einem solchen Schritt entschlossen haben.

Der Misserfolg seiner Verhandlungen mit Maximilian von Habsburg konnte eine solche Entscheidung veranlasst haben. Der Großfürst war von ihm in seiner Ehre stark gekränkt worden und wollte einen Gegenschlag mit Echo in Europa austeilen. Der Peterhof und Livland waren die einzigen Schmerzpunkte des Reiches, auf die er einwirken konnte, um dem westlichen Europa sowohl die Kraft seines Reiches als auch seine Macht kundzutun. Grundsätzlich lässt sich feststellen, dass die Demonstration seiner Macht in massiver und darum lange nachwirkender Form dem Charakter Ivans III. vollkommen entsprach; darüber hinaus war er sehr rachsüchtig. Der Verfasser der vor kurzem veröffentlichten Biographie Ivans III., Nikolaj Borissov, schreibt in dieser Hinsicht: „Die ganze Lebensgeschichte von ihm weist darauf hin, dass er Kränkungen

\footnotetext{
${ }^{96}$ LEKUB II, 1, 95, S. 76.

${ }^{97}$ Marina BESSUDNOvA, Likvidacija ganzejskoj kontory $v$ Velikom Novgorod: novaja versija (Die Schließung [oder: Aufhebung] des Hansekontors in Groß-Novgorod: eine neue Version), in: Čelo 2006, 1(35), S. 14-19, hier S. 17-19.

"Ix Anti Selart, Zur Geschichte der Russen in Livland um die Wende des 15. zum 16. Jahrhundert: Der Vorwand zur Schließung des St. Peterhofes in Novgorod im Jahr 1494, in: Norbert Angermann (Hg.). Städtisches Leben im Baltikum zur Zeit der Hanse. Zwölf Beiträge zum 12. Baltischen Seminar, Lüneburg 2003, S. 177-210, hier S. 210.
}

${ }^{99}$ Borisov, Ivan III. (wie Anm. 21), S. 512-513 
nie verzieh, obwohl er nicht immer die Möglichkeit hatte, sich unverzüglich zu rächen". ${ }^{100}$ Im Peterhof wohnten die Kaufleute aus Deutschland und Livland, das im Verlauf der russisch-habsburgischen Verhandlungen oft als dem Kaiser gehöriges Land auftrat. Der Hof galt deshalb als „Teil des Reiches“, auf den, und das ist wichtig, der Großfürst die Möglichkeit hatte, mit Gewalt einzuwirken.

Nach Aleksandr Zimin gehörte Ivan III. zu denjenigen Politikern, die „,durch die Planmäßigkeit bei der Lösung der gestellten Aufgaben gekennzeichnet waren", ${ }^{101}$ und diese Charakteristik wird auch durch die Ausführung der Novgoroder Aktion bestätigt. Bis zum Herbst 1494 wären die Schließung des Hansekontors in Novgorod und die Handlungen gegen Reval nicht zweckmäßig gewesen. Folgende Umstände bestimmten die Termine ihrer Durchführung:

1. Die Gesandten des Großfürsten, die in Italien und Dänemark verhandelt hatten, sollten über Reval und Livland nach Novgorod heimkehren, darum musste man bis zu ihrer Heimkehr diesen Weg sicher machen. Im Sommer 1494 kamen sie zurück. Die Nachrichten über ihre Heimkehr stehen in der Voskresenskaja letopś' gerade vor dem Bericht über die Schließung des Peterhofs. ${ }^{102}$ Man kann auch mit größter Wahrscheinlichkeit annehmen, dass Reval im Sommer 1494 aufhörte, europäische Fachleute, die vom Großfürsten für bestimmte Dienstleistungen ins Land gerufen wurden, nach Moskau weiterreisen zu lassen. ${ }^{103}$ Dort wurde man sich der Tatsache bewusst, dass der Herrscher den Weg Novgorod - Reval - Lübeck nicht mehr brauchte.

2. Der Großfürst wartete darauf, dass die Kaufleute, die im Sommer im Kontor gehandelt hatten, abgereist waren; an ihrer Stelle kamen die sog. „Wintergäste“, die den Keller der St. Peterskirche mit Waren füllten und viel Geld für den Einkauf russischer Waren, einschließlich kostbarer Pelze, in den Händen hielten. Vielleicht war die Verzögerung der Verhandlungen mit Remmelingrode und Schrowe in Moskau im September und Oktober 1494 auch durch diesen Umstand bedingt. Remmelingrode meinte doch, dass der Großfürst mit der Schließung des Peterhofs eine große Geldsumme erzielen könnte. ${ }^{104}$ Tatsächlich brachte die Beschlagnahme des Hanseeigentums dem Großfürsten 96.000 Mark ein. ${ }^{105}$

\footnotetext{
${ }^{100}$ Ebd. S. 405.

${ }^{101}$ ZimIN, Rossija na rubeže XV-XVI stoletij (wie Anm. 26), S. 104.

${ }^{102}$ Voskresenskaja letopis' (wie Anm. 31), S. 228.

${ }^{103}$ Ende Mai 1494 richtete der Lübecker Johann von Unkel an den Revaler Rat die Empfehlung, die Handlungen der russischen Sendboten, die Fachleute und Knechte nach Russland begleiteten zu stören. LEKUB II, 1, 2.

${ }^{104}$ LEKUB 1I. 1, 9.5.

${ }^{105}$ LEKUB I, 1, 80.
} 
Die Verträge, die Ivan III. 1493 mit dem Großfürsten von Litauen Alexander und vor allem mit dem dänischen König Johann abgeschlossen hatte, entschädigten ihn teilweise für den erfolglosen Ausgang der Verhandlungen mit Maximilian, und dies um so mehr, als Hauptpunkte der russisch-dänischen Vereinbarungen, nämlich ein dynastisches Eheund Militärbündnis, denjenigen ähnelten, die 1491 mit Maximilian ausgehandelt worden waren. Der nachfolgende russisch-schwedische Krieg hatte keine wirtschaftlichen, sondern politische Folgen, darunter die Machtdemonstration gerade an der Grenze zur katholischen Welt, wie sie schon mit dem Bau Ivangorods im Jahre 1492 oder der Schließung des Hansekontors in Novgorod 1494 zum Ausdruck gebracht worden war.

Man möchte meinen, dass sich Ivan wie andere Herrscher, die von den Nachkommen „die Großen“ genannt wurden, in seinen Handlungen nur von großen Gesichtspunkten hätte leiten lassen. Aber Ivan der Große lebte nicht außerhalb seiner Zeit; diese war noch durch heftige Gefühle und auffallende Taten geprägt, die für den gegenwärtigen Rationalismus und Pragmatismus nicht immer begreiflich sind. Es ging damals um den Status des neu entstehenden Russischen Staates und seine Stellung im politischen System Europas, die auch im Titel des Herrschers ihren Niederschlag fanden. Die Großfürsten von Moskau verzichteten im Kampf um die Bestätigung ihrer Zarenwürde nie auf Gewalt. Der Enkel Ivans III. verlängerte die von diesem begründete Tradition und löste, um die europäische Anerkennung seiner Zarenwürde zu bekommen, einen der erbittertsten Konflikte der Neuzeit aus, den Livländischen Krieg. 